\title{
Article \\ Influence of the Metal Incorporation into Hydroxyapatites on the Deactivation Behavior of the Solids in the Esterification of Glycerol
}

\author{
Gabriela Mota ${ }^{1}$, José Vitor C. do Carmo ${ }^{1}$, Camila B. Paz ${ }^{1}$, Gilberto D. Saraiva ${ }^{2}$, Adriana Campos ${ }^{3}$, \\ Gian Duarte ${ }^{3}$, Edson C. da Silva Filho ${ }^{4}\left(\mathbb{D}\right.$, Alcineia C. Oliveira ${ }^{1, * \mathbb{D}}$, João M. Soares ${ }^{5}$, \\ Enrique Rodríguez-Castellón ${ }^{6}\left[\right.$ and Elena Rodríguez-Aguado ${ }^{6}$
}

1 Departamento de Química Analítica e Físico-Química, Campus do Pici, Universidade Federal do Ceará, Bloco 940, Fortaleza 60455-760, Ceará, Brazil; gabrielamotab@alu.ufc.br (G.M.); vitor.costa@alu.ufc.br (J.V.C.d.C.); milabpaz@gmail.com (C.B.P.)

2 Faculdade de Educação Ciências e Letras do Sertão Central, Universidade Estadual do Ceará, Quixadá 63902-098, Ceará, Brazil; gilberto.saraiva@uece.br

3 Centro de Tecnologias Estrategicas do Nordeste-CETENE, Cidade Universitária, Recife 50740-545, Pernambuco, Brazil; adriufrpe@gmail.com (A.C.); gian.duarte07@gmail.com (G.D.)

4 Departamento de Química, Campus Universitário Ministro Petrônio Portella, Universidade Federal do Piauí, Teresina 64049-550, Piauí, Brazil; edsonfilho@ufpi.edu.br

5 Departmento de Física, Universidade do Estado do Rio Grande do Norte-UERN, BR 110-km 48, R. Prof. Antônio Campos Costa e Silva, Mossoró 59625-620, Rio Grande do Norte, Brazil; joaomsoares@gmail.com

check for updates

Citation: Mota, G.; Carmo, J.V.C.d.; Paz, C.B.; Saraiva, G.D.; Campos, A.; Duarte, G.; Filho, E.C.d.S.; Oliveira,

A.C.; Soares, J.M.;

Rodríguez-Castellón, E.; et al Influence of the Metal Incorporation into Hydroxyapatites on the Deactivation Behavior of the Solids in the Esterification of Glycerol.

Catalysts 2022, 12, 10. https:// doi.org/10.3390/catal12010010

Academic Editors: Maria A. Goula, Charles Xu and Gabriel Morales

Received: 19 October 2021

Accepted: 17 December 2021

Published: 23 December 2021

Publisher's Note: MDPI stays neutral with regard to jurisdictional claims in published maps and institutional affiliations.

Copyright: (c) 2021 by the authors. Licensee MDPI, Basel, Switzerland. This article is an open access article distributed under the terms and conditions of the Creative Commons Attribution (CC BY) license (https:// creativecommons.org/licenses/by/ $4.0 /)$
6 Departamento de Química Inorgánica, Facultad de Ciencias, Universidad de Málaga, 29071 Málaga, Spain; castellon@uma.es (E.R.-C.); aguadoelena5@gmail.com (E.R.-A.)

* Correspondence: alcineia@ufc.br; Tel./Fax: +55-853-366-9008

\begin{abstract}
The effects of the metal incorporation into hydroxyapatites on the deactivation behavior of the solids were examined in the esterification of glycerol (EG) reaction. The introduction of $\mathrm{Cu}, \mathrm{Co}$, or $\mathrm{Ni}$ ions by ion exchange in calcium-deficient hydroxyapatites resulted in active catalysts for the EG reaction. The metal contents were varied from 2.0 to $17.0 \%$, providing better performances at rather high metal contents. Part of metal species existed in the hydroxyapatite lattice structure and also as isolated $\mathrm{Cu}^{2+}, \mathrm{Ni}^{2+}$, and $\mathrm{Co}^{2+}$ entities on the surface, as shown by XPS and EPR. The effects of the reaction temperature, reaction time, and glycerol to acetic acid molar ratios were deeply investigated. The spent solids used in this study were characterized by XRD, FTIR, SEM-EDS, chemical analyses, $E P R$, and XPS. The $\mathrm{Cu}^{2+}-\mathrm{OH}$ acid pairs could promote a superior catalytic performance of $\mathrm{Cu}-$ containing hydroxyapatites due to the resistance of these solids against leaching of the active species, which is even better than those of $\mathrm{Co}$ and Ni-containing counterparts with high metal contents. $\mathrm{Cu}$ into hydroxyapatite had a good reusability and long-term utilization for five consecutive cycles of $24 \mathrm{~h}$ under a glycerol to acetic acid molar ratio of 0.25 at $80^{\circ} \mathrm{C}$, and longer reaction times provide triacetin formation. This was due to the fact that $\mathrm{Cu}$ was stabilized by interacting with $\mathrm{Ca}, \mathrm{PO}_{4}$, and $\mathrm{OH}$ sites into the hydroxyapatite lattice, being highly active for the EG reaction. The results also revealed that isolated $\mathrm{Cu}^{2+}$ sites played an important role in enhancing the glycerol conversion, intrinsically due to the $\mathrm{Cu}$-containing hydroxyapatites ability to avoid strong adsorption of glycerol oligomers on the catalytic sites.
\end{abstract}

Keywords: esterification; hydroxyapatite; $\mathrm{Cu}$; glycerol; triacetin

\section{Introduction}

Glycerol is regarded as a renewable and industrially important source of raw material for the production of value-added chemicals, such as glycerol carbonates, esters (acetins), and ethylene glycol, among others [1-3]. Crude glycerol is a chemical raw material obtained from the synthesis of biodiesel [4-7]. Due to the emerging large-scale worldwide production of biofuels, crude glycerol is forecasted to flood the market and poses especially serious risks 
to humans because of the improper disposal of large quantities of the crude tri-alcohol [1,4]. Hence, the increasingly severe problem of this by-product pollution has received great attention for developing new technologies with lower costs and higher efficiency conversion of crude glycerol. Although purification of glycerol has been successfully applied to transform crude glycerol, in recent years, this technology is much more expensive and has ubiquitous negative impact on the environment $[1,6,8]$.

Therefore, catalytic processes for the valorization of glycerol, including glycerol carboxylation with $\mathrm{CO}_{2}$ to glycerol carbonates, polymerization, electrooxidation, dehydration, esterification, hydrogenation, and oxidation reactions, are considered to be among the most efficient and greenest alternative methods for converting glycerol into valuable chemical intermediates [6-10]. Among these catalytic routes, the glycerol esterification (acetylation) reaction has attracted growing attention all over the world as a potential to transform glycerol into its esters $[2,8,11]$.

The esterification of glycerol with acetic acid or acetic anhydride is a single step reaction that produces esters of glycerol, namely glyceryl monoacetates (acetins). The reactions are represented by the following equation (Figure 1).

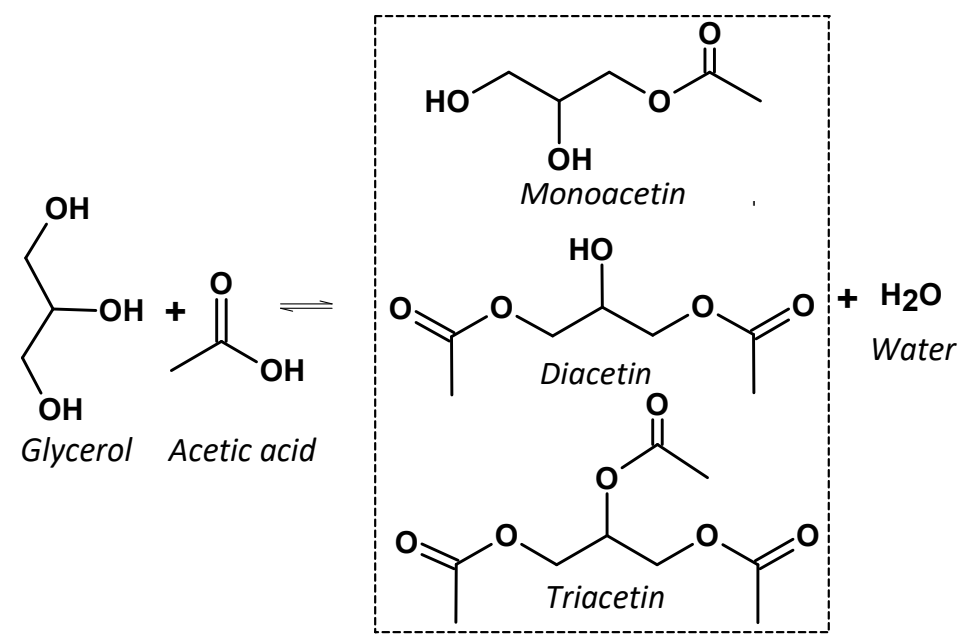

Figure 1. Scheme of the glycerol esterification reaction with acetic acid.

In the parallel-series reaction, the first step consists of glycerol reacting with acetic acid to obtain the monacetin (MAG) isomer. The process continues with the consecutive reaction of monacetin with another acetic acid molecule giving glyceryl diacetate, the so-called diacetin (DAG). The subsequent reaction of the latter ester with another acetic acid molecule produces glyceryl triacetate, triacetin (TAG). In all aforementioned steps, water molecules are then eliminated and the reaction equilibrium should be controlled because of water formation [1,12].

Noteworthy is that monacetin is applied in food industry, solvent for dyes, manufacturing of explosives, and biodegradable polymers $[6,13]$. Diacetin is used as plasticizer and additive for fuels and as a softening agent [1,14]. Triacetin is the glycerol ester of high molecular weight that finds application as humectants, fuel components, and solvents for diluting drugs and organic substances [1,15].

The esterification of glycerol in the presence of acetic acid (EG reaction) has typically been performed with catalysts-containing basic, acid and redox sites [1-16]. Obviously, the acidic catalysts are among the most investigated solids in the EG reaction owing to their high glycerol conversions provided by both Brønsted and Lewis acid sites $[1-3,10,17]$. Nonetheless, the selectivities to glycerol acetates depend mainly on the acidity of the catalysts, especially those possessing acid sites of medium to strong strengths, in spite of their low selectivities to the acetins [1,2]. Moreover, the leaching of the acid sites should implicitly deactivate the solids in the EG reaction, along with the catalyst deactivation, by unavoidable action of water as a poison adsorbed on the active sites. This may cause 
leaching of active components in the reaction medium and possible hydrolysis of the formed esters, as well $[1,12,15]$.

On the basis of these two facts, a challenge in this field is designing water-tolerant oxide catalysts that have redox and Lewis acid sites capable of promoting the EG reaction at relatively low temperatures. Earlier works have demonstrated that the hydrophilic character of phosphates-based catalysts applied in the glycerol transformations provided water-tolerant solids possessing redox and acid-base sites, compared with that of traditional transition metal oxide catalysts $[17,18]$. In addition, these studies revealed that Lewis acid sites present in these catalysts mediate glycerol conversion more efficiently than do Brønsted acid ones; hence, catalyst lifetime and resistance against deactivation greatly improved the performance of the solids.

The tuning of easily synthesizable, non-expensive, environmentally friendly, and water-tolerant catalysts for the EG reaction is very important because these types of catalysts are expected to play a more extended role in the transformation of glycerol. Therefore, hydroxyapatite phosphates fulfill these requirements, as the texture, structure, and surface morphology, as well as their electronic properties, play a key role for good catalytic performances [18]. Hydroxyapatites (HAP) are important phosphate-containing calcium materials being acid-base and water-tolerant solids. In general, HAPs display a stoichiometric chemical composition of $\mathrm{Ca}_{10}\left(\mathrm{PO}_{4}\right)_{6}(\mathrm{OH})_{2}$ with a Ca/P molar ratio of 1.67, whereas deficient HAP (non-stoichiometric) with $\mathrm{Ca} / \mathrm{P}<1.67$ have the general formula $\mathrm{Ca}_{10-\mathrm{x}}\left(\mathrm{HPO}_{4}\right)\left(\mathrm{PO}_{4}\right)_{6-\mathrm{x}}(\mathrm{OH})_{2-\mathrm{x}}\left(\mathrm{H}_{2} \mathrm{O}\right)_{\mathrm{x}}$, where $0<\mathrm{x} \leq 1$ [19-21]. Besides, other compositions of HAPs-based solids are detailed as follows: $\beta$-tricalcium phosphate $(\beta-\mathrm{TCP})$ with a formula of $\mathrm{Ca}_{3}(\mathrm{PO} 4)_{2}$ and $\mathrm{Ca} / \mathrm{P}$ ratio of 1.5 ; octacalcium phosphate $(\mathrm{OCP})$ having general formula $\mathrm{Ca}_{8} \mathrm{H}_{2}\left(\mathrm{PO}_{4}\right) 6 \cdot \mathrm{xH}_{2} \mathrm{O}$ with a $\mathrm{Ca} / \mathrm{P}$ ratio of 1.33 ; calcium hydrogen phosphate $\left(\mathrm{CaHPO}_{4}\right)$ with a $\mathrm{Ca} / \mathrm{P}$ ratio of 1 and calcium pyrophosphate $(\mathrm{DCP})\left(\beta-\mathrm{Ca}_{2} \mathrm{P}_{2} \mathrm{O}_{7}\right)$ with a $\mathrm{Ca} / \mathrm{P}$ ratio of $1[19,20]$. In addition, the so-called over-stoichiometric HAP or rich HAP (HAP R) possessing a Ca/P molar ratio above 1.67 can be found [20]. Hence, hydroxyapatites exhibit a wide variety of structures and electronic properties as catalysts or catalyst supports $[17,18]$.

To the best of our knowledge, there are not reports on the use of an acidic solid based on HAPs as catalysts for EG reaction with acetic acid. In this contribution, we aim to examine the catalytic properties of the HAP-based catalysts for the esterification of glycerol with acetic acid and also to find the relationships between the physicochemical properties and the catalytic behaviors of the solids. Besides, catalysts composed of such HAP may have low to moderate acidic strength through introducing cations in their structures via isomorphic substitution of $\mathrm{Ca}^{2+}$ ions by another bivalent cation, namely $\mathrm{Co}^{2+}, \mathrm{Ni}^{2+}$, or $\mathrm{Cu}^{2+}$. This also allows for redox properties and, thus, higher glycerol conversions in addition to the improved performance for catalyst reuses. The reasons for the deactivation behavior of the solids are also investigated.

\section{Results and Discussion}

\subsection{Catalytic Performance and Reusability in the Esterification of Glycerol}

The effect of the reaction time on the catalytic performance of solids is investigated in the EG reaction in the presence of acetic acid. For comparison, a copper-based oxide catalyst, namely CuNB and Ni-containing HAP, are also evaluated under the same conditions (Figure 2).

The glycerol conversion rises as the reaction time precedes, in all cases, reaching the maximum activity within $6 \mathrm{~h}$. The reference CuNB catalyst is an exception, since glycerol conversion diminishes steeply over time, and, thereafter, the glycerol conversion falls achieving negligible values in $6 \mathrm{~h}$, except for the $\mathrm{CuNB}$ reference catalyst. For $\mathrm{Cu}-$ containing HAP (Figure 2a), the glycerol conversion achieves $28 \%$ in the first $2 \mathrm{~h}$ of EG reaction; then, it reaches values in the $16-45 \%$ range, with the reaction time prolonging to $6 \mathrm{~h}$. 


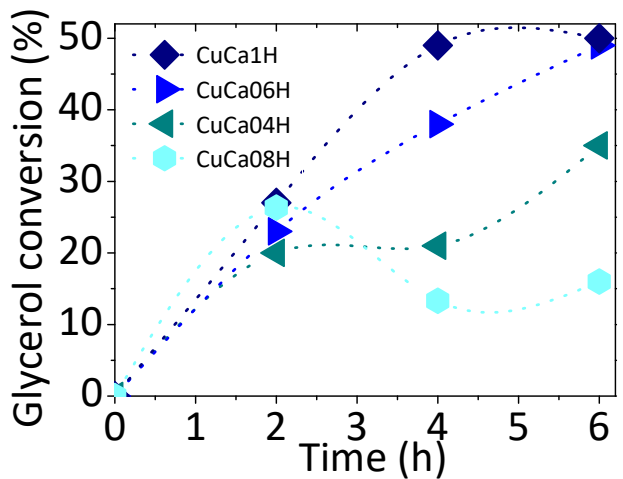

(a)

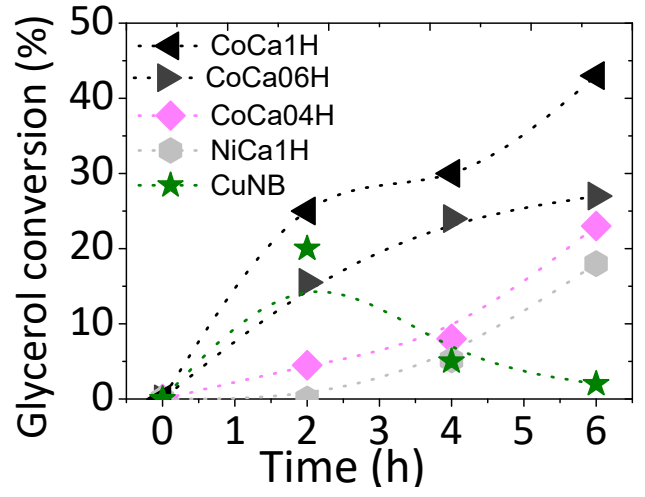

(b)

Figure 2. Time-dependence evolution of glycerol conversion for the solids studied: (a) Cu-containing hydroxyapatites and (b) co-containing hydroxyapatites, $\mathrm{NiCa} 1 \mathrm{H}$ and $\mathrm{CuNB}$ catalysts. Reaction conditions: $75 \mathrm{mg}$ of catalyst, glycerol to acetic acid molar ratio of 0.25 , and reaction temperature $=80^{\circ} \mathrm{C}$.

In the case of Co-containing HAP, it exhibits similar trends in terms of increasing glycerol conversions during the time course of the reaction (Figure 2b). Particularly, a reference Ni-containing HAP catalyst possessing $15.7 \mathrm{wt} . \%$ of nickel (Materials and Methods section) shows $18 \%$ of glycerol conversion between 4 and $6 \mathrm{~h}$ of EG reaction. This result is not quite good compared with those the $\mathrm{Cu}$ and Co-HAP counterparts. Importantly, bare $\mathrm{CaH}$ hydroxyapatite is inactive in the reaction due to the lack of acidic or redox sites that catalyze the reaction.

The contribution of acidity needs to be considered into the activities of the hydroxyapatitebased catalysts for the EG reaction. When the contribution of surface Lewis acid sites, e.g., $\mathrm{Ca}^{2+}$ cations, and basic oxygen coming from $\mathrm{PO}_{4}{ }^{3-}$ ions, e.g., $\mathrm{O}^{2-}$ interacting pairs of HAPs, may occur, this configuration allows a strong polarization of chemical bonds between hydrogen and water forming a hydration multilayer [20]. Considering that the acidity of HAPs may be higher with adding metals into their matrices and augment upon increasing the metal contents, all metal-containing HAPs are allowed to have high acidity and, thus, adsorb more water on their surfaces.

The metal-containing HAPs in study have acid sites of medium to strong strengths, depending on the metal presence with $\mathrm{Cu}$-based solids possessing high $\mathrm{Cu}$ contents holding strong acidity [18]. As expected, the Cu-containing HAPs are hardly deactivated by water adsorption (Figure 2a), even if they possess high acidity. Further spent solids characterizations demonstrate that high glycerol conversion and recyclability of these catalysts are achievable due to their stabilities during the EG reaction.

Noteworthy is that conversions of glycerol over the $\mathrm{Cu}$-containing $\mathrm{CuNB}$ catalyst are lower than all samples studied (Figure 2b). Chemical analysis of the spent CuNB after $6 \mathrm{~h}$ of reaction indicates that the nominal loading of $\mathrm{Cu}$ of ca. $17.0 \mathrm{wt} . \%$ (Materials and Methods section) drops to $1.4 \mathrm{wt} . \%$. This result, together with the lack of a stable matrix to stabilize $\mathrm{Cu}$ ions, is somewhat surprising, revealing the fact that, even in the presence of high copper contents initially, the existence of active $\mathrm{Cu}$ ions in low interaction with a matrix on CuNB catalyst makes the solid inactive in the reaction due to leaching effects. In addition, the reaction solution of $\mathrm{CuNB}$ becomes a vivid blue, and glycerol conversion reaches null conversion in $6 \mathrm{~h}$ of reaction.

Regarding the selectivities, monoacetin is preferentially formed in short reaction times, e.g., less than $2 \mathrm{~h}$, whereas diacetin and triacetin products are obtained as the reaction proceeds. Moreover, triacetin glycerol ester is the dominant product at the end of the reaction. Table 1 illustrates the selectivities of the obtained products within $6 \mathrm{~h}$ of EG reaction. The triacetin product is preferable among all the glycerol esters produced at $80{ }^{\circ} \mathrm{C}$, as illustrated in Table 1 . This can be expected because of the high glycerol conversion achieved at this temperature that enables, in fact, the consecutive reaction of the mono and diacetin derivatives with acetic acid to convert into triacetin glycerol acetylated 
product. It is important to note that all catalysts have minor monoacetin and diacetin products formation, compared with triacetin, despite over $37.5 \%$ of the selectivity towards monacetin in $\mathrm{CoCa} 06 \mathrm{H}$ catalyst. Since the low acidity of the $\mathrm{CoCa} 06 \mathrm{H}$ catalyst should be considered [18], the glycerol conversion is low resulting in high amounts of monacetin.

Table 1. The product selectivities for the catalysts tested in $6 \mathrm{~h}$ of EG reaction. Reaction conditions: $75 \mathrm{mg}$ of catalyst, glycerol to acetic acid molar ratio of 0.25 , and reaction temperature $=80^{\circ} \mathrm{C}$.

\begin{tabular}{ccccc}
\hline Catalysts & Monoacetin (\%) & Diacetin (\%) & Triacetin (\%) & Others (\%) \\
\hline CuCa1H & 6.9 & 7.6 & 10.8 & 74.6 \\
CuCa08H & 5.8 & 7.9 & 5.0 & 81.1 \\
CuCa06H & 13.9 & 7.6 & 14.5 & 63.8 \\
$\mathrm{CuCa04H}$ & 8.7 & 14.2 & 16.1 & 60.9 \\
$\mathrm{CoCa} 1 \mathrm{H}$ & 9.1 & 13.4 & 13.8 & 63.6 \\
$\mathrm{CoCa} 06 \mathrm{H}$ & 37.5 & 8.8 & 12.0 & 41.6 \\
$\mathrm{CoCa04H}$ & 10.9 & 2.9 & 21.6 & 64.5 \\
$\mathrm{NiCa} 1 \mathrm{H}$ & 1.7 & 2.1 & 3.5 & 92.6 \\
\hline
\end{tabular}

The $\mathrm{CaCo} 08 \mathrm{H}$ has negligible conversions, along with the reaction time, due to the very low cobalt content (Materials and Method section) that has leached out during the EG reaction. In the last stage of the time course reaction, the by-products of oligomerization of triacetin with diacetin, monoacetin, or both, are obtained in greater amounts. Under similar conditions, the acidic $\mathrm{Cu}$-containing HAP is rather selective for by-products compared to their Co and Ni analogues, while the activity in the EG reaction is correlated to the acidity and amount of copper ions in the hydroxyapatites. Moreover, the significant change in product selectivity towards others by-products in these cases is associated with the reaction pathways.

In agreement, these observations are closely related to the esters of glycerol formation through the Fischer esterification mechanism [14]. It is well known that the overall activity in the EG reaction is attributable to the acidity of the heterogeneous catalysts $[8,14]$. As a general rule, a proton coming from the acidic catalysts attacks the acetic acid, forming an intermediate that surfers rearrangements (Figure 3, step 1). Then, the intermediate formed in the step 1 reacts with either terminal or central hydroxyl group of glycerol (step 2), which is indeed double-bonded to carbon. This pathway of such a reaction mechanism involves the acylium ion intermediate, as it is polarized with a fair amount of positive charges (step 3). The literature reports raise the possibility of this route is the rate-determine step of the EG reaction $[14,18]$.

In the following step, the acid site-acetic acid complexes are likely to involve glycerol molecules rather than that of other acetic acid ones. Subsequently, the obtained complex suffers from multiple nucleophilic attacks of the hydroxyl groups of glycerol. In the sequence, the monoacetin formation (step 4) is energetically less favorable than the additional esterification due to higher stability of the intermediate formed. Thus, the reaction proceeds with the consecutive attack of an acetic acid molecule to monoacetin forming diacetin (step 5), which is accompanied by the release of the water molecule. Finally, the respective triacetin is formed (step 6), as a result of diacetin reaction with another acetic acid molecule and water formation [14,22-25]. According to the results shown in Figure 2, the catalytic performance for the EG reaction demonstrates that all hydroxyapatites catalysts are active in the studied reaction.

Moreover, the effect of reaction time on the conversion of glycerol for HAP-based catalysts reveals that the activities increase with the reaction time in the series of solids $\mathrm{CuCa} 1 \mathrm{H}>\mathrm{CoCa} 1 \mathrm{H}>\mathrm{NiCa} 1 \mathrm{H}$, having CuNB null conversion in $6 \mathrm{~h}$. These series of solids are correlated with the acidity and, thus, the presence of the metals in the corresponding solids, as well as with their metal content, e.g., high $\mathrm{Cu} / \mathrm{Ca}$ atomic ratios (Materials and Methods section). 


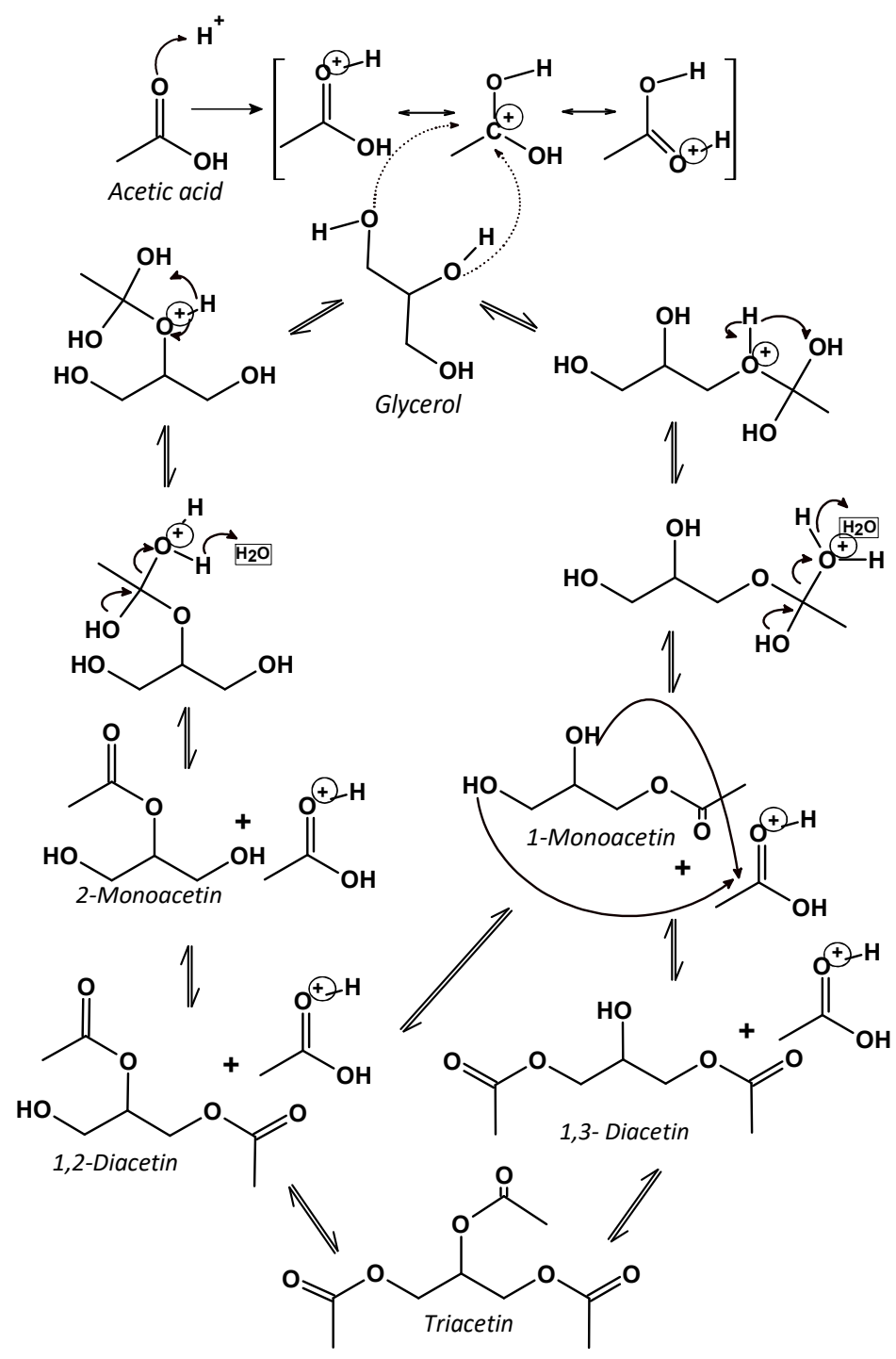

Figure 3. Illustration of the proposed mechanism for glycerol esterification with acetic acid reaction.

The high acidity and metal contents enhance glycerol conversion to the target products for $\mathrm{Cu}$-containing HAPs. Our previous findings illustrate that the incorporation of $\mathrm{Cu}$ into the hydroxyapatites tends to cause an effective increasing of Lewis and Brønsted acid strengths [18]. In line, the results indicate that rising the overall acidity with $\mathrm{Cu}$ content gives more active sites for strong glycerol adsorption on the $\mathrm{Cu}$ surface; consequently, the catalytic EG reaction might be accelerated, which is consistent with the order of reaction activity shown. These data also support the hypothesis that CuNB has a higher amount of $\mathrm{Cu}$ of ca. $17.0 \mathrm{wt} . \%$, ranging in loading of $\mathrm{CuCa} 1 \mathrm{H}$ catalyst is prone to be deactivated along of the EG reaction. Again, the fact that active $\mathrm{Cu}^{2+}$ active species by itself activates glycerol without the participation of a robust matrix or support can be totally discarded. Thereby, the $\mathrm{Cu}$ active sites need to be incorporated in well dispersed sites of a stable matrix, such as that of HAPs, to be able to promote a redox site in EG reaction.

Conversely, it is anticipated that an increasing Co incorporation into HAPs not only decreases the acidity, as found elsewhere [18], but also promotes the lower availability of Co active sites for the reaction due to Co clusters formation and, thus, affects their activity to catalyze the reaction.

At the same time, the percentage of $\mathrm{Ni}$ in the $\mathrm{NiCa} 1 \mathrm{H}$ catalyst is very high (Materials and Methods section); however, the glycerol conversion is poor, compared to the other HAPs counterparts. The differences among the catalysts may be due to the low acidity 
and mainly related to the fact that the $\mathrm{Ni}$ has better ability to catalyze others reaction with glycerol, for example, glycerol reforming, hydrogenolysis, and dehydration [18,24]. This results in the lowest performance of $\mathrm{NiCa} 1 \mathrm{H}$ catalyst in the EG reaction, among all HAPs studied.

After these preliminary experiments, $\mathrm{Cu}$-containing HAPs have a better performance in the EG reaction; thus, they are chosen to conduct the catalytic activities tests in the next section.

\subsection{Influence of the Reaction Temperature and Glycerol to Acetic Acid Molar Ratios}

Temperature and glycerol to acid acetic molar ratios are vital factors influencing the catalytic performance towards glycerol esterification. Despite the favorable results obtained over $\mathrm{Cu}$-containing HAPs, the interaction between the $\mathrm{Cu}$ species and the HAP structure has not yet been fully understood, and more research is still being done. Importantly, Co-containing HAPs and $\mathrm{NiCa} 1 \mathrm{H}$ catalysts are also evaluated at different temperatures, but glycerol conversions results are considered to be very low at temperatures below $80{ }^{\circ} \mathrm{C}$.

Therefore, the experiments are conducted using the most active solids studied in the previous section. Figure 4 illustrates the influence of the reaction temperature on the catalytic performance of the solids in the EG reaction on $\mathrm{Cu}$-containing HAPs. Glycerol conversions increased up to $2 \mathrm{~h}$ and then reached maximum activity within $6 \mathrm{~h}$ of the reaction. At mild temperatures, such as $40{ }^{\circ} \mathrm{C}$, the solids have the lowest glycerol conversions monitored every $1 \mathrm{~h}$. This is attributed to the fact that there is an insufficient amount of heat needed for an endothermic reaction at $40^{\circ} \mathrm{C}$. Simultaneously, the majority of monoacetin is formed with a $70 \%$ of conversion in $6 \mathrm{~h}$ at $40^{\circ} \mathrm{C}$. A possible explanation for the appearance of the monoester of glycerol is that the acylium ion intermediate formation occurs through the ionic attack of a hydroxyl group of glycerol on the carbonyl group of methyl acetate $[2,26]$. Consequently, this step of acylium ion transformation to monoacetin on the catalyst surface is the stage that determines the rate of the reaction and monoacetin might become predominant, as found elsewhere [18,26].

Furthermore, the glycerol conversion also increased appreciably from 40 to $80^{\circ} \mathrm{C}$ over all the solids studied, irrespective to the $\mathrm{Cu}$ contents, while the selectivity for the formation of others by-products is almost unaffected, but that of triacetin decreases at $80{ }^{\circ} \mathrm{C}$. When the setting temperature is $60^{\circ} \mathrm{C}$, the conversions increased greatly over the course of the reaction for $\mathrm{CuCa} 06 \mathrm{H}$ and $\mathrm{CuCa} 04 \mathrm{H}$, reaching more than $17 \%$ of glycerol production. On the contrary, at the same temperature of $60{ }^{\circ} \mathrm{C}$, the glycerol conversion slightly increases from 1 and $11 \%$ in $4 \mathrm{~h}$ and then decreases to $2 \%$ over $\mathrm{CuCa} 1 \mathrm{H}$, indicating a solid deactivation at $60{ }^{\circ} \mathrm{C}$. Likewise, $\mathrm{CuCa} 08 \mathrm{H}$, possessing lower $\mathrm{Cu}$ contents, e.g., lower $\mathrm{Cu} / \mathrm{Ca}$ atomic ratios (Materials methods section), exhibits poor catalytic activity among the evaluated $\mathrm{Cu}$-based HAP catalysts. As further demonstrated by spent catalyst characterizations, leaching of the active sites causes a serious decline of the glycerol conversion.

On the basis of these trends, high temperatures, such as $80^{\circ} \mathrm{C}$, favored the reaction as the glycerol conversions increased from 2 to $50 \%$. In all catalytic tests, the selectivities to the esters of glycerol products are low and remain constant in a short-term catalytic run, in opposition to by-products formation. Moreover, the values shown in Table 1 correspond to the steady state conditions in $6 \mathrm{~h}$.

The esterification of glycerol with acetic acid is a consecutive reaction that consists of the acetylation of glycerol to the monoacetin ester, in addition to water formation; the protonation of the remaining hydroxyl groups of glycerol is an endothermic reaction that is impeded by steric factors and/or interaction with the active sites on the catalyst surface [26]. Thereby, glycerol esters of high molecular weight, such as triacetin, and their oligomers are favored at elevated temperatures as shown in this work. This can explain the fact that the triacetin production increased continuously over time, and, finally, it is possible to find out that the main by-products formed are their oligomers in $6 \mathrm{~h}$. However, in some catalysts, monoacetin and diacetin are also produced to a negligible extent (the maximum selectivity 
of these products is always kept below 14\%), also depending on the $\mathrm{Cu}$ contents and the acidity of the solids.
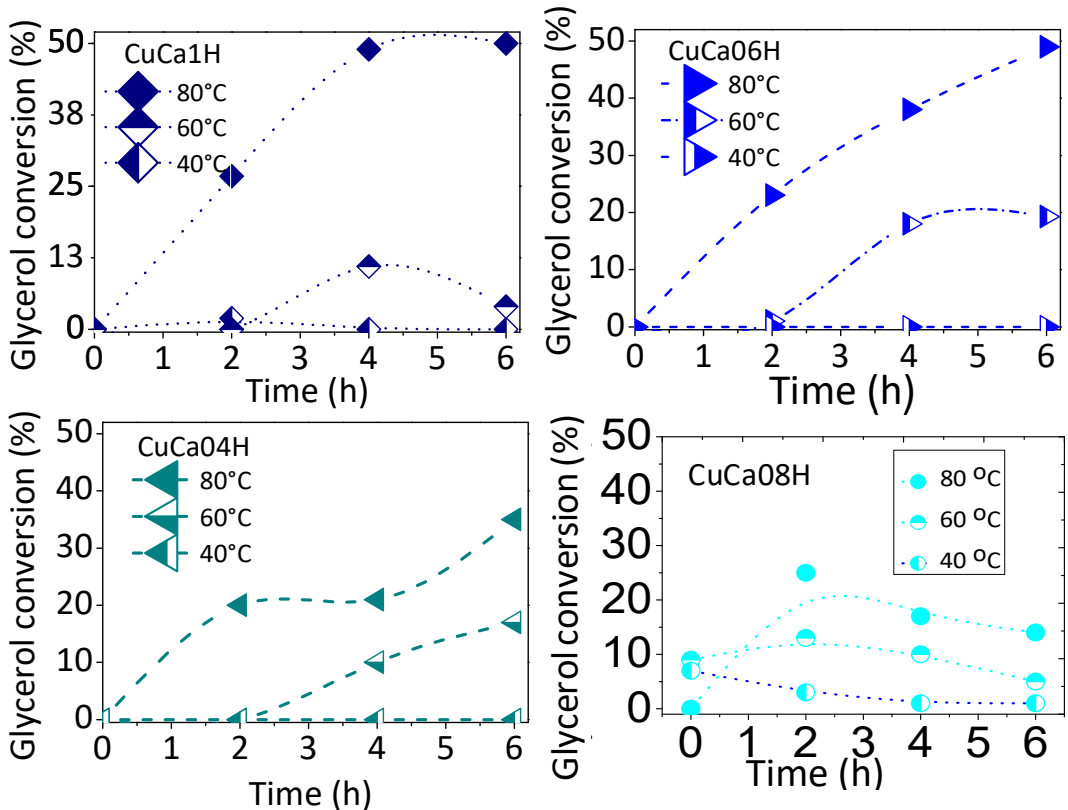

Figure 4. Time courses for glycerol conversion in the EG reaction over the most active catalysts. The reaction temperature was varied from 40 to $80^{\circ} \mathrm{C}$. Reaction conditions: $75 \mathrm{mg}$ of catalyst with a glycerol to acetic acid molar ratio kept constant at 0.25 .

Therefore, the temperature dependence of the catalytic performance indicates that $80^{\circ} \mathrm{C}$ is regarded as a suitable reaction temperature, when considering the tendencies between glycerol conversion and product selectivities. The use of $\mathrm{Cu}$-containing HAPs, including variations in the copper content, is found to improve the metal-matrix interaction and, hence, enhance the stability of the solid. As a consequence, high amount Cu into HAP gives better performances in the EG reaction, although the overall triacetin production is low due to the elevated acidity of the solids.

The influence of glycerol to acetic acid molar ratios on the catalytic performance of the most active solids is shown in Figure 5. The stability of $\mathrm{Cu}$-containing HAPs is investigated under EG reaction conditions at $80{ }^{\circ} \mathrm{C}$ and glycerol to acetic acid molar ratios varying from 0.25 to 0.50 . All catalysts display increased glycerol conversions upon increasing the reaction time from 1 to $6 \mathrm{~h}$ for glycerol to acetic acid molar ratios of 0.25 . When the glycerol to acetic acid molar ratios increase from 0.25 to 0.5 , the glycerol conversion drops markedly over the course of the reaction time. For instance, glycerol conversion changes from 52 to $23 \%$ over $\mathrm{CuCa} 1 \mathrm{H}$ within $6 \mathrm{~h}$ of reaction.

The effect of the glycerol to acetic acid molar ratios on the catalytic performances of $\mathrm{CuCa} 06 \mathrm{H}, \mathrm{CuCa} 04 \mathrm{H}$, and $\mathrm{CuCa} 08 \mathrm{H}$ catalysts illustrates the fact that, at glycerol to acetic acid molar ratios higher than 0.25 , glycerol conversions are affected significantly due to different $\mathrm{Cu}$ contents. For example, at glycerol to acetic acid molar ratios of 0.33 , part of the $\mathrm{Cu}$ in the HAP matrix seems to be leached from the $\mathrm{CuCaO6H}, \mathrm{CuCa04H}$, and $\mathrm{CuCa08H}$ catalysts; thus, a glycerol conversions decay is observed within $6 \mathrm{~h}$.

This suggests that the EG reaction could be affected by the interaction of the reactants with $\mathrm{Cu}$ included into the HAP lattice, in longer reaction times. In other words, the $\mathrm{CuCa06H}, \mathrm{CuCa04H}$, and $\mathrm{CuCa} 08 \mathrm{H}$ catalysts possessing $\mathrm{Cu}$ amount less than 1.01 have $\mathrm{Cu}$ species existing out of HAP structure, which are preferentially leached to the reaction solution, rather than those of the HAP lattice. Therefore, small acetic acid amounts appear to slow down the EG reaction due to the lesser amount of molecules available to form the reactive intermediate in the rate determining step of the overall reaction, at high glycerol to acetic acid molar ratios up to 0.25 . 

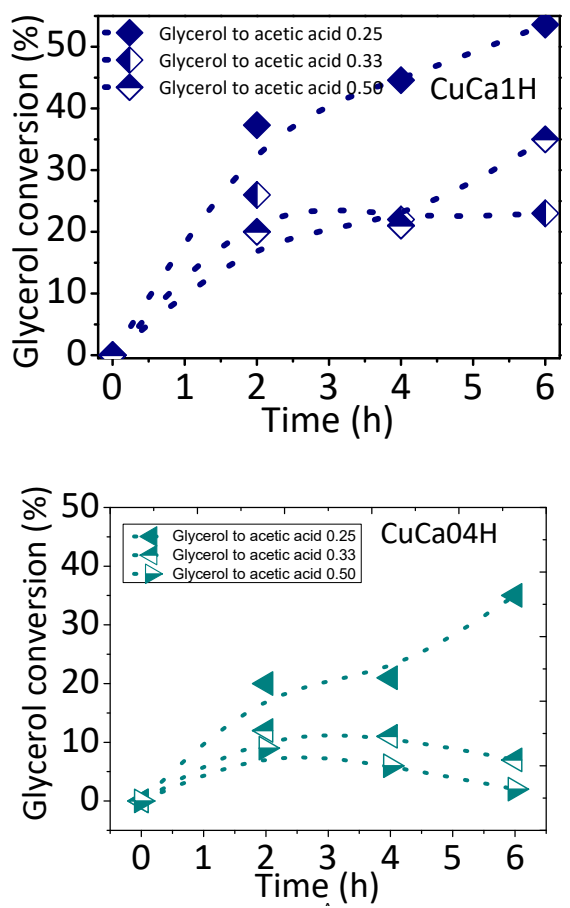
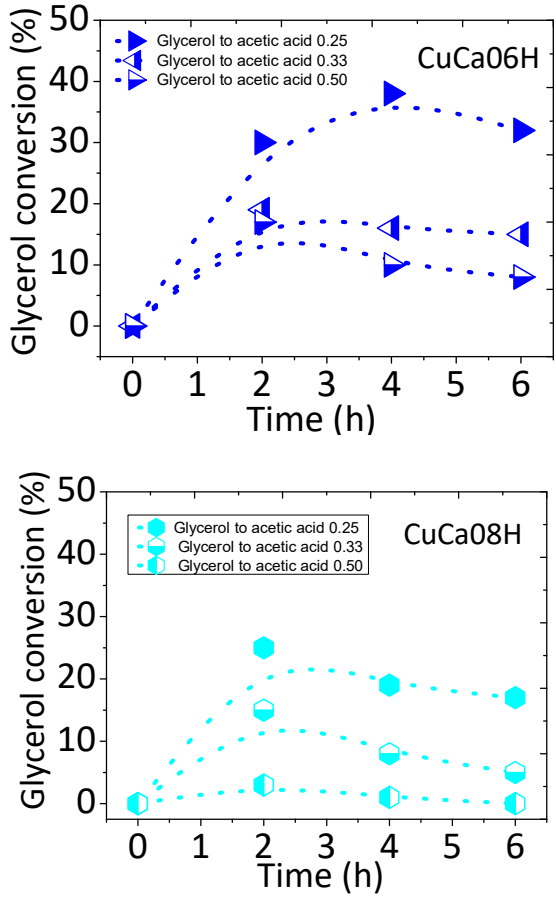

Figure 5. Evolution of glycerol conversion as a function of the reaction time using different glycerol to acetic acid molar ratios over the most active catalysts in the EG reaction. Reaction conditions: $75 \mathrm{mg}$ of catalyst and glycerol to acetic acid molar ratios varying from 0.25 to 0.50 . The reaction temperature was kept at $80^{\circ} \mathrm{C}$.

Furthermore, the glycerol conversions of both $\mathrm{CuCa} 06 \mathrm{H}$ and $\mathrm{CuCa} 08 \mathrm{H}$ are lowered to values below $10 \%$ in glycerol to acetic acid molar ratio of 0.50 , while an opposite trend is seen in $\mathrm{CuCa} 1 \mathrm{H}$. By increasing the glycerol to acetic acid molar ratios, the glycerol conversions drastically shift to zero over the $\mathrm{CuCa} 08 \mathrm{H}$ catalyst having the lowest $\mathrm{Cu}$ content. Later, spent catalyst characterization demonstrates that $\mathrm{CuCa} 08 \mathrm{H}$ has negligible copper content in $6 \mathrm{~h}$ of reaction. As found elsewhere [2], small amounts of acetic acid provide more glycerol molecules to react than in the reaction condition with larger amounts of acetic acid counterpart. This could be nicely correlated with fact that more copper active surface species interacts promptly with glycerol, when the glycerol to acetic acid molar ratio is of 0.25 . Since intermediate acetylated species are formed during the rate-determining step, glycerol conversions increase more linearly with low glycerol to acetic acid molar ratios. In addition, the high $\mathrm{Cu}$ loadings contributes almost exclusively to the acid sites needed for the reaction as in case of $\mathrm{CaCu} 1 \mathrm{H}$, whereas its hydroxyapatite matrix acts only as a stabilizer preventing the aggregates of $\mathrm{Cu}$ particles formation, thus, resulting in a more effective catalyst for the reaction.

Simultaneously, the selectivity for triacetin increases continuously, while that of monoacetin and diacetin is almost negligible. Early studies on the esterification of glycerol indicate that an excess of acetic acid, i.e., lower glycerol to acetic acid molar ratios, may dilute the solution shifting the equilibrium for the products formation in the esterification of glycerol with acetic acid reaction [2,26]. Additionally, $\mathrm{Cu}$ ions into the HAP matrix of $\mathrm{CuCa} 1 \mathrm{H}$ and its water tolerance makes the solid very active in the EG reaction.

It is worthy of mention that the HAPs in study are slight calcium-deficient hydroxyapatites having $\mathrm{Ca} / \mathrm{P}<1.67$ [18]. As the $\mathrm{Ca} / \mathrm{Me}(\mathrm{Me}=\mathrm{Cu}$, $\mathrm{Co}$ or $\mathrm{Ni})$ atomic ratios decrease, the metal content increases due to the substitution of $\mathrm{Ca}^{2+}$ ions by $\mathrm{Me}^{2+}$ ones into the HAP matrix, resulting in an electrical imbalance of the structure [18]. It is believed that changing of $\mathrm{Ca} / \mathrm{P}$ ratio in the HAP structures to obtain $\mathrm{Ca}$-deficient hydroxyatites may cause a great increase in the distance between acidic and basic sites, provoking a drop in water adsorption strength and surface hydrophilicity, as well [27]. On the other 
hand, we assume that the high surface hydrophilicity of the calcium-deficient $\mathrm{Cu}$-based HAPs under study arises from their unique structure, in which part of phosphate ions are replaced with hydrophosphates. As a result of such a phenomenon, numerous acidic sites become available, mainly because of the intrinsic property of the HAPs and $\mathrm{Cu}$ to enhance the acidity with increasing $\mathrm{Cu}$ content in the matrix. This is consistent with the acidity measurements in our early study on hydroxyapatites [18]. Besides, some preferable $\mathrm{Cu}$ sites in the $\mathrm{Cu}$-containing HAPs, that may strongly adsorb water as $\mathrm{H}_{3} \mathrm{O}^{+}$, do not present water deactivation, as the $\mathrm{Cu}$ content and acetic acid increased, differently from most Co-containing HAPs counterparts.

Thus, the $\mathrm{CuCa} 1 \mathrm{H}$ catalyst seems to be very active and allowed $40-50 \%$ glycerol conversion under the optimized reaction conditions within $6 \mathrm{~h}$ of the EG reaction. In addition, the monoacetin formation at the beginning of the reaction is water-soluble, and thereby its fast transformation into triacetin, which is indeed water insoluble at higher glycerol to acetic acid ratios, is likely to occur at longer reaction times.

Optimized reactions conditions are a reaction temperature of $80^{\circ} \mathrm{C}$, and the glycerol to acetic acid molar ratio kept constant at 0.25 . Such conditions allow high glycerol conversions and selectivity for triacetin during the EG reaction. Additionally, $\mathrm{Cu}$ species are mostly responsible for the better catalytic behavior of solids in the EG reaction compared with the $\mathrm{Ni}$ and Co hydroxyapatite counterparts. Thus, the activity of the solids is not only strongly dependent on the $\mathrm{Cu}^{2+}$ included on the hydroxyapatite lattice but also of the surface concentration of $\mathrm{Cu}^{2+}$ species, with increased values leading to better catalytic performances under similar reaction conditions. On the contrary, the $\mathrm{Cu}$ loss might be also responsible for the low performances of some solids in the EG reaction, presumably because of $\mathrm{Cu}$ leaching from hydroxyapatite matrix.

\subsection{Reusability of the Most Active Catalysts}

The most active solids, e.g., $\mathrm{CuCa} 1 \mathrm{H}, \mathrm{CuCa} 06 \mathrm{H}$, and $\mathrm{CoCa} 1 \mathrm{H}$ catalysts, were used in five consecutive catalytic cycles of glycerol transformation, initially using $75 \mathrm{mg}$ of catalysts. Recyclability experiments using all other solids in the first catalytic cycle of reuse show negligible glycerol conversions. Between the catalytic cycles, the catalyst was recovered by filtration and washed, in order to remove weakly adsorbed compounds. Then, the solids were employed as a catalyst in the subsequent catalytic test. When the mass of catalysts diminished during the catalytic run, $25 \%$ of the catalysts are added to the reaction.

After using CoCa1H for two consecutive runs (Figure 6), a drastic fall in glycerol conversion clearly suggests the lack of stability of the Co sites into the HAP matrix. Further EDS analyses demonstrate that the leaching of cobalt species from the solid surface possibly going away in the filtrate. Interestingly, triacetin is detected with $17 \%$, among the products with no significant loss in the catalyst. In the case of $\mathrm{CuCa06H}$, significant effects of the $\mathrm{Cu}$ presence and its content into the HAP lattice are observed on glycerol conversion. Accordingly, the three successive cycles of use of $\mathrm{CaCu} 06 \mathrm{H}$ holds the glycerol conversion between 48 and $26 \%$. After this period beyond $72 \mathrm{~h}$ of continuing reaction, the glycerol conversion starts to decline gradually to $2 \%$ after five cycles. It is important is to note that monoacetin and diacetin are absent, albeit the triacetin selectivity is $18 \%$, whereas others are obtained as major products.

Contrarily, $\mathrm{CuCa} 1 \mathrm{H}$, which has a high $\mathrm{Cu}$ content and high acidity, shows a lowering in glycerol conversion from 50 to $40 \%$ in the third cycle. After five consecutive cycles, $\mathrm{CuCa} 1 \mathrm{H}$ does not show considerable change in glycerol conversion with triacetin selectivity kept in the $18-21 \%$ range along all runs of $\mathrm{Cu}$-containing catalysts. Thus, $\mathrm{CuCa} 1 \mathrm{H}$ is by far more active than the $\mathrm{CaCu06H}$ counterpart due to the $\mathrm{Cu}$ species into the HAP matrix in the former solid prevailing triacetin product, in addition to the products of oligomerization of glycerol acetals. Interestingly, $\mathrm{CuCa} 1 \mathrm{H}$, possessing high water affinity due to its hydrophilicity, does not present strong deactivation, which demonstrates the water inhibitory effect of the solid in longer reaction times. 


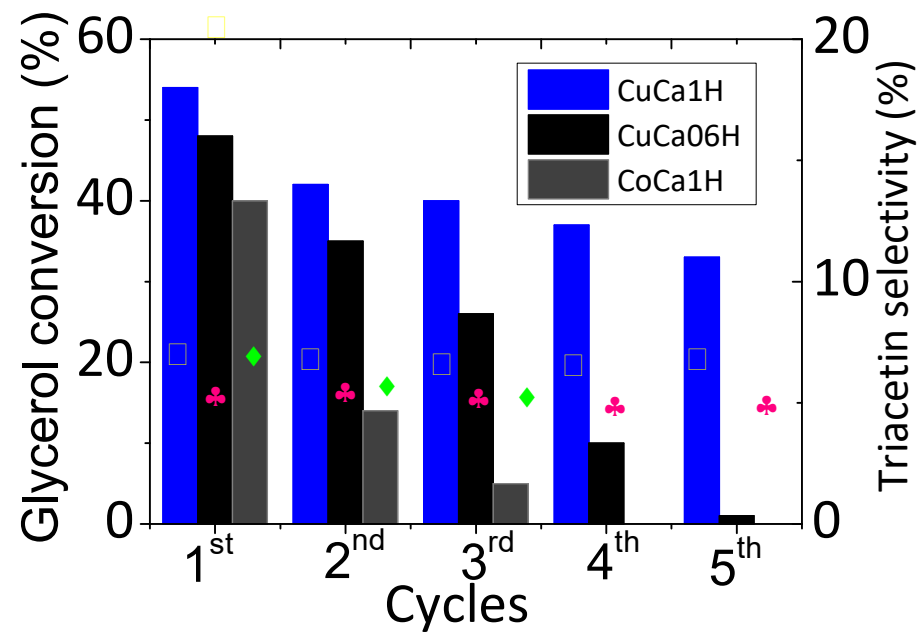

Figure 6. Recyclability studies over the most active catalysts. Reaction conditions: $75 \mathrm{mg}$ of catalyst, glycerol to acetic acid molar ratios kept constant at 0.25 . The reaction temperature was kept at $80{ }^{\circ} \mathrm{C}$. The symbols $(\square)$, (\$), and $(\checkmark)$ indicate the triacetin selectivities values for $\mathrm{CuCa} 1 \mathrm{H}, \mathrm{CuCa} 06 \mathrm{H}$, and CoCa1H catalysts, respectively.

The catalytic performances of solids in the EG reaction under continuous catalytic cycles in a long-term stability runs reveal that $\mathrm{CuCa} 1 \mathrm{H}$ and $\mathrm{CuCa06H}$ have good performance, e.g., glycerol conversions superior to $30 \%$ at $80{ }^{\circ} \mathrm{C}$, glycerol to acetic acid molar ratio of 0.25 , at least for cycles taking place in 3 days. On the contrary, $\mathrm{CoCa} 1 \mathrm{H}$, possessing similar Co content, shows deactivation after the $3^{\text {rd }}$ cycle of reaction, achieving near-zero glycerol conversion. This result is close to the expectations suggested by the XRD, FTIR, EPR, XPS, and SEM-EDS characterizations of spent catalysts. The characterizations will confirm the low stability of the Co and Ni-containing HAPs compared to Cu-based hydroxyapatites, and $\mathrm{Co}$ and $\mathrm{Ni}$ particles leaching to be further shown by results.

\subsection{Spent Catalysts Characterizations}

A detailed study of the fresh HAP catalysts characterizations takes into consideration existing literature data [18].

\subsubsection{Structure of the Spent Samples}

Figure 7a shows the $\mathrm{X}$-ray diffraction (XRD) patterns of the spent catalysts. The peaks positions at $2 \theta=25.9(002), 31.7(210), 34.4(211), 40.0(310), 50.2(213), 51.7(321)$, and 53.6 (410) match well with the main reflections of the crystalline structure for HAPs (P62/m space group; JCPDS ${ }^{\circ}$ 09-0432).

The XRD patterns also reveal that the HAPs correspond to the major phases, which could be assigned to stability of the hexagonal structure, as seen in the fresh solid [18]. Moreover, the XRD patterns of Cu-containing HAPs exhibit sharp peaks, some of them having high intensities. This is especially true for $\mathrm{CuCa} 1 \mathrm{H}$ and $\mathrm{CuCa} 08 \mathrm{H}$ samples.

Of importance, a very small peak at around $2 \theta=18.8^{\circ}$ may correspond to the (110) plane of tricalcium phosphate ( $\left.\beta-\mathrm{TCP}, \mathrm{Ca}_{3}\left(\mathrm{PO}_{4}\right)_{2}\right) ; R 3 c$ space group JCPDS $\mathrm{n}^{\circ}$ 00-009-0169), especially for $\mathrm{CuCa} 1 \mathrm{H}, \mathrm{CuCa} 06 \mathrm{H}$, and $\mathrm{CuCa} 08 \mathrm{H}$ spent samples. This indicates that the $\beta$-TCP could be formed in the catalysts having high amounts of $\mathrm{Cu}$ or possessing $\mathrm{Cu}^{2+}$ species leached out of the HAP lattice, as latter confirmed by the SEM-EDS, EPR, and XPS results. Thus, the XRD patterns display an evident influence of $\mathrm{Cu}$ amounts on the composition and stability of the HAPs phases. 


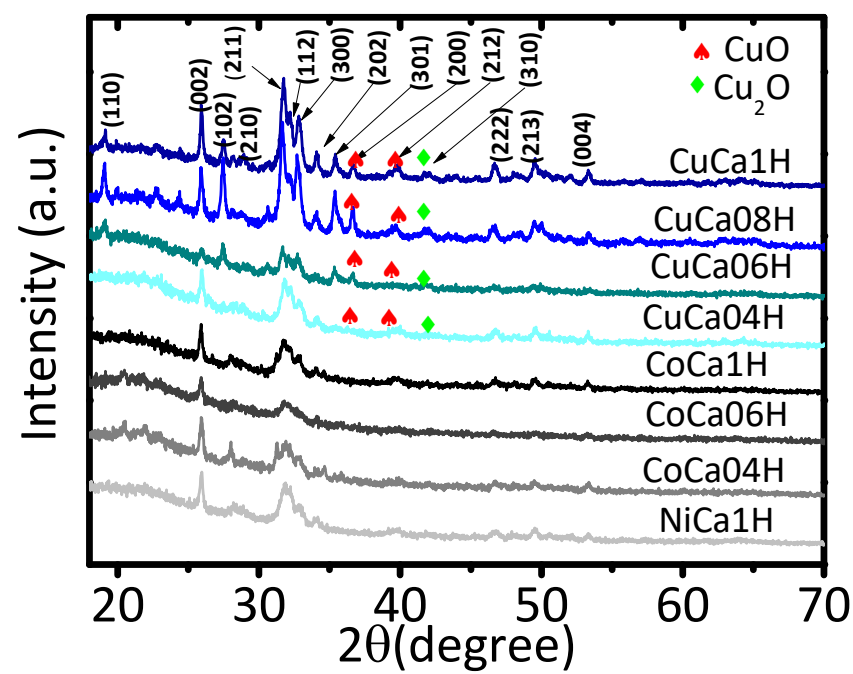

(a)
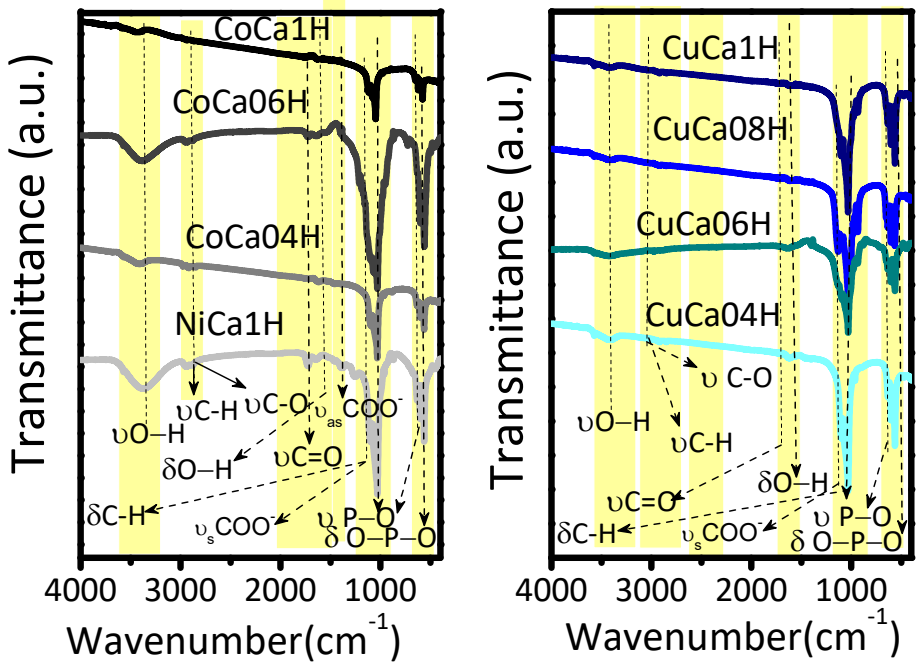

(b)

Figure 7. (a) XRD patterns and (b) FTIR spectra of the spent catalysts. The solids were tested under the following reaction conditions: $75 \mathrm{mg}$ of catalyst, glycerol to acetic acid molar ratio of 0.25 , and reaction temperature of $80^{\circ} \mathrm{C}$.

In addition, the main diffraction peaks of $\mathrm{CuO}$ appear at $2 \theta=35.5(002)$ and $38.5^{\circ}$ (111). Concomitantly, a peak of $\mathrm{Cu}_{2} \mathrm{O}$ at $2 \theta=42.1^{\circ}(200)$ could be overlapped to that of (301) reflection of HAP, as found for $\mathrm{Cu}$-based hydroxyapatite catalysts $[28,29]$. Therefore, the substitution of $\mathrm{Ca}$ ion by $\mathrm{Cu}$ into the HAP lattice likely occurred in the fresh solid without changes into the hydroxyapatite structures during the catalytic test. However, some peaks arising from $\mathrm{CuO}$ and $\mathrm{Cu}_{2} \mathrm{O}$ are indicative of the $\mathrm{Cu}$ leaching from the HAP lattices after running the solid in the EG reaction.

As found elsewhere, the formation of apatites, such as $\beta$-tricalcium phosphate and calcium hydrogen phosphates, may result rather from the lack of $\mathrm{Ca}$ in HAP structure than from the presence of $\mathrm{Cu}[19,20]$, but these phases are not observable in the XRD patterns. Besides, the peaks indexed to be from oxyapatites as monetite, i.e., $\left(\mathrm{Ca}\left(\mathrm{HPO}_{4}\right.\right.$, JCPDS $\left.n^{\circ} 70-1425\right)$, and oxyhydroxyapatite, e.g., libethenite $\left(\left[\mathrm{Cu}_{2}(\mathrm{OH})\left(\mathrm{PO}_{4}\right)\right]\right.$, both phases previously detected in the fresh sample [18], are not visible in the sample. It could indicate the lower thermo stability of monetite and libethenite phases during the EG reaction. This result is in accordance with the findings that show the stability of the libethenite phase occurs at temperatures below $200{ }^{\circ} \mathrm{C}$ [30]. 
Moreover, the hexagonal HAP phase appears predominantly in the spent $\mathrm{Co}$ and $\mathrm{Ni}$-containing HAPs catalysts (Figure 7a). Additionally, these hydroxyapatites are poorly crystallized with broad diffraction patterns in comparison with those of $\mathrm{Cu}$-based solids. Importantly, the occurrence of any additional peaks of other phases would permit the assumption that the $\mathrm{Co}$ and $\mathrm{Ni}$ species would be included into the HAP lattice, even after the reaction and, hence, would reveal other factors associated with the deactivation of the solids.

FTIR spectroscopy measurements are used as a complementary tool to a deeper investigation the structural features of the solids after the catalytic tests. The FTIR spectra show broad stretching bands at around $3500 \mathrm{~cm}^{-1}$ (Figure $7 \mathrm{~b}$ ). As an indication of the hexagonal HAP structure, this band is typically associated with structural $v(\mathrm{OH})$ groups, as seen in the fresh solid [18]. It is well-known that these absorption bands arise from either structural $\mathrm{OH}^{-}$groups of the bulk HAP situated inside the channels or structural surface $\mathrm{OH}^{-}$groups in HAPs [29-32]. Interestingly, the absorption band at $3500 \mathrm{~cm}^{-1}$ is wide, being located in the same region as those of the physisorbed water generated from the EG reaction (Figure 1).

Moreover, the corresponding bending $\mathrm{H}-\mathrm{O}-\mathrm{H}$ vibrations are detected through the small band at about $1630 \mathrm{~cm}^{-1}$ [33], in all solids. Noteworthy is that the broad and intense band of the $\mathrm{OH}$ groups, centered at about $3500 \mathrm{~cm}^{-1}$ becomes flatter upon increasing Co and $\mathrm{Cu}$ contents with the effect being predominant on the latter series of solids. Combining with the catalytic results, the influence of the metal contents is also found for $\mathrm{Cu}$-containing HAP catalysts, which demonstrates that activities are higher than that of Co-based solids. Therefore, a synergistic effect involving $\mathrm{Cu}$ species, especially those of $\mathrm{Cu}$ species included into the HAP, and HAP structure itself, is identified as a possible explanation for the catalytic results. Thereby, FTIR measurements illustrate through the $\mathrm{OH}$ groups that the water does not deactivate the $\mathrm{Cu}$-based solids, at high $\mathrm{Cu}$ contents.

Besides, the FTIR spectra also exhibit broad bands with shoulders at about 960-1080 and $560 \mathrm{~cm}^{-1}$, which are characteristic of the degenerate bending modes of $v(\mathrm{P}-\mathrm{O})$ and $\delta(\mathrm{O}-$ $\mathrm{P}-\mathrm{O})$ from $\mathrm{PO}_{4}{ }^{3-}$, respectively. An intense absorption band along with other contributions with lower intensities are due to doubly degenerate asymmetric $\mathrm{O}-\mathrm{C}-\mathrm{O}$ stretching modes at $1400-1500 \mathrm{~cm}^{-1}$, which are indeed originated from $\mathrm{CO}_{3}{ }^{2-}$ species [31,32]. The presence of the latter bands corroborates the fact that the HAPs in study are stable towards the EG reaction conditions. In addition, the other carbonate bands at around $840-900 \mathrm{~cm}^{-1}$, along with their doubly degenerate planar bending mode at $650-750 \mathrm{~cm}^{-1}$, are not evident, since they overlap with the band due to phosphate groups. From the FTIR results, no significant change in the HAP structures is observed, in agreement with XRD results.

Meanwhile, FTIR spectra of the spent catalysts depict absorption bands typical for acetins and glycerol adsorbed on solid surface. For instance, at around $1000 \mathrm{~cm}^{-1}$, the typical symmetric deformations of $\mathrm{C}-\mathrm{H}$ in methyl groups are clearly seen. In addition, at $1050 \mathrm{~cm}^{-1}$, the stretching vibrations of epoxy groups can be overlapped with the HAP bands. Moreover, the characteristic bands of molecular vibrations of carbonyl compounds, such as $-\mathrm{C}-\mathrm{C}-\mathrm{O}$ and $\mathrm{C}=\mathrm{O}$, derived from glycerol esters are assigned at 1200 and $1700 \mathrm{~cm}^{-1}$, respectively [34]. Specifically, the prominent band at around $1720 \mathrm{~cm}^{-1}$ matches well with that of the stretching vibrations of $\mathrm{C}-\mathrm{O}$ from carboxylic moieties, probably from the acetic acid reactant. The stretching vibration of $\mathrm{C}-\mathrm{O}-\mathrm{C}$ bonds, symmetric $\mathrm{C}=\mathrm{O}$ stretching and vs(COO-) are seen at around $1317 \mathrm{~cm}^{-1}$, along with asymmetric $\mathrm{C}=\mathrm{O}$ stretching modes at $1520 \mathrm{~cm}^{-1}$, with these bands probably coming from the oligomers would be possible. Later, the presence of adsorbed hydrocarbons on solid surface and deposition of oligomers on the surface is confirmed by SEM-EDS and XPS results.

Therefore, FTIR measurements confirm the XRD results revealing the maintenance of the HAP structure in all solids, after the catalytic tests. In addition, the existence of the less abundant hydroxyl groups and adsorption bands of the acetins groups in the $\mathrm{Cu}$-containing HAPs suggest these solids are more resistant against either leaching of the acid sites or water deactivation. This ensures a boosting of the catalytic performance in 
terms of stability of the $\mathrm{Cu}$ included into the HAP structure, in comparison with those of $\mathrm{Ni}$ and Co-containing HAPs counterparts. In addition, these features allow better catalytic results as different amounts of $\mathrm{Cu}$ are included the hydroxyapatites. FTIR measurements reveal slight chemical changes in the HAP structures do not affect the stability of the main phase. Contrarily, the effects of leaching of Co and Ni species from HAP structure during the catalytic runs are also suggested.

\subsubsection{Morphology and Composition}

Figure 8 shows the SEM micrographs of spent solids. All spent metal-hydroxyapatites exhibits a nearly bunch of bundles particles (Figure 8), while their surfaces are smooth forming platelets. Some of the catalysts, e.g., $\mathrm{CuCa} 08 \mathrm{H}$ and $\mathrm{CoCa} 1 \mathrm{H}$, show the agglomeration of the bundles resulting in further densification, along with the production of clusters shaped particles. It is remarkable that the formation of bundles or nanorods well-defined particles is reported for hydroxyapatites $[18,35,36]$. According to the results of SEM, all spent catalysts well retain their morphological features after the catalytic tests, with some of these particles being agglomerated on the external surface of the solids.

Assuming insignificant effects of the EG reaction conditions on the morphology, the obtained samples are examined with respect to their surface composition through EDS elemental mappings (Figure 9). As it can be seen, the $\mathrm{Ca}, \mathrm{O}$, and $\mathrm{P}$ elements are very homogeneously distributed on the bundled $\mathrm{Cu}$-containing HAP surfaces. Besides, C element arises from the adsorbed hydrocarbons, such as glycerol acetins and oligomers, on solid surfaces, as previously observed by FTIR measurements. Contrarily, the Cu element distribution seems to not be homogeneous on the surfaces of the $\mathrm{CuCa08H}$ and $\mathrm{CuCa04H}$ hydroxyapatites, owing to the leaching of the $\mathrm{Cu}$ species from these solids. Likewise, the spent $\mathrm{Co}$ and $\mathrm{Ni}$-containing HAPs depict $\mathrm{Co}$ and $\mathrm{Ni}$ unevenly distributed throughout the particles surfaces.

The surface element compositions obtained from the EDS spectra for spent samples are illustrated in Table 2. The $\mathrm{Ca}, \mathrm{O}$, and $\mathrm{P}$ elements originating from HAP structures are evident in all solids, again confirming the XRD and FTIR assumptions that the HAP structure is maintained in all solids, after the EG reaction. Importantly, the surface Ca/P ratio atomic percentages of the fresh calcium deficient HAP decreased from 1.6 to 1.4 , as the copper content increased [18]. Additionally, the elemental composition of spent $\mathrm{CuCa} 1 \mathrm{H}$ is found to be very much similar to that of the fresh solid, e.g., Ca 23.8, P 14.0, and O 52.0\%, as listed in Table 2. Accordingly, it is found that the stoichiometric ratio of $\mathrm{Ca} / \mathrm{P}$ of fresh $\mathrm{CuCa} 1 \mathrm{H}$ is 1.64 [18], which again confirms the stability of the solid, even after the catalytic test. On the other hand, slightly lower $\mathrm{Ca} / \mathrm{P}$ ratios values of $1.4,1.5$, and 1.2 are obtained for $\mathrm{CuCa08H}, \mathrm{CuCa06H}$, and $\mathrm{CuCa0} 4 \mathrm{H}$ spent samples, respectively. These results mean that a quantitative loss of $\mathrm{Ca}$ ions is observed during the reaction for samples containing low $\mathrm{Cu}$ amounts, and, consequently, these samples depict low activity in the EG reaction.

The amount of $\mathrm{Cu}$ on solid surface varies from 5.3 to $9.8 \%$ (Table 2), which is comparable with the values observed in the bulk samples, e.g., 2.5-17.0 wt.\% [18]. A tentative explanation for $\mathrm{Cu}$ occurrence on solid surface may be that the $\mathrm{Cu}$ ions migrates to solid surface after the catalytic test, especially for $\mathrm{CuCa} 1 \mathrm{H}$, but no significant loss of $\mathrm{Cu}$ is observed in the solid. By contrast, samples possessing lower amounts of $\mathrm{Cu}$, such as $\mathrm{CuCa08H}$, $\mathrm{CuCa06H}$, and $\mathrm{CuCa04H}$, show a major $\mathrm{Cu}$ loss on their surfaces with respect to $\mathrm{CuCa} 1 \mathrm{H}$, which, in turn, may lead to the low performance of these solids in the reaction. Important to note is that $\mathrm{C}$ is found to be on spent $\mathrm{CuCa} 1 \mathrm{H}$ surface in low amounts of ca. 0.08 , which suggests a weak adsorption of the products of the reaction on solid surface. Moreover, the amounts of $\mathrm{C}$ are found to be 46.6, 22.3, 21.0, and 30.7\% for $\mathrm{CuCa08H}, \mathrm{CuCa} 06 \mathrm{H}, \mathrm{CuCa} 04 \mathrm{H}$, and $\mathrm{CoCa} 1 \mathrm{H}$, respectively (Table 2). This suggests that the activity of $\mathrm{CuCa} 1 \mathrm{H}$ is not mainly controlled by the acidity but also to the ability of solid to inhibit water and hydrocarbon adsorption on $\mathrm{Cu}$ actives sites. 


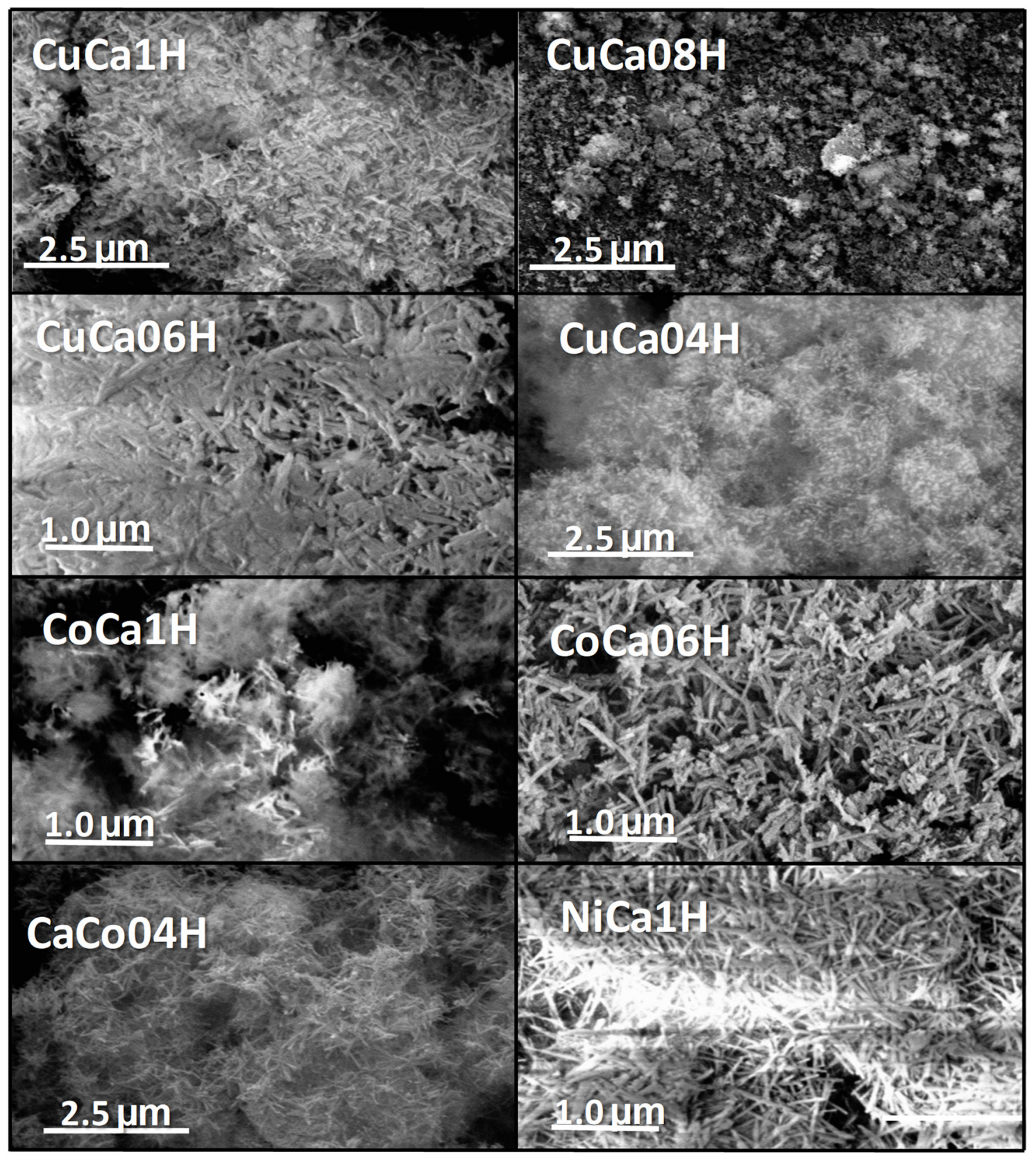

Figure 8. SEM micrographs of the spent solids. The solids are evaluated in the EG reaction at $80{ }^{\circ} \mathrm{C}$ and glycerol to acetic acid molar ratio of 0.25 .

Table 2. Atomic percentages of the elements obtained from EDS spectra. The solids are evaluated in the EG reaction at $80^{\circ} \mathrm{C}$ and glycerol to acetic acid molar ratio of 0.25 .

\begin{tabular}{|c|c|c|c|c|c|c|c|}
\hline Catalyst & Ca (\%) & $P(\%)$ & $\mathrm{C}(\%)$ & O (\%) & Co $(\%)$ & $\mathrm{Cu}(\%)$ & $\mathrm{Ni}(\%)$ \\
\hline CuCa1H & 23.8 & 14.0 & 0.08 & 52.0 & - & 6.8 & - \\
\hline $\mathrm{CuCa} 08 \mathrm{H}$ & 7.4 & 4.9 & 46.6 & 34.3 & - & 9.8 & - \\
\hline $\mathrm{CuCa06H}$ & 15.1 & 9.8 & 22.3 & 43.0 & - & 7.6 & - \\
\hline $\mathrm{CuCa} 04 \mathrm{H}$ & 42.8 & 18.8 & 21.0 & 33.9 & - & 5.3 & - \\
\hline $\mathrm{CoCa} 1 \mathrm{H}$ & 16.6 & 8.4 & 30.7 & 43.5 & 0.8 & - & - \\
\hline $\mathrm{CoCa} 06 \mathrm{H}$ & 27.1 & 16.9 & 13.8 & 35.3 & 6.9 & - & - \\
\hline $\mathrm{CoCa} 04 \mathrm{H}$ & 24.6 & 11.8 & 36.8 & 23.3 & 3.1 & - & - \\
\hline $\mathrm{NiCa} 1 \mathrm{H}$ & 57.1 & 23.1 & - & - & - & - & 1.0 \\
\hline
\end{tabular}






Figure 9. EDS mapping of the corresponding SEM micrographs for spent solids. The solids are evaluated in the EG reaction at $80{ }^{\circ} \mathrm{C}$ and glycerol to acetic acid molar ratio of 0.25 .

Additionally, the dissimilarities of the surface $\mathrm{Co}$ and $\mathrm{Ni}$ distributions in $\mathrm{Co}$ and Ni-containing HAPs illustrate the lack of stability of the samples, consistent with their poor performance in the EG reaction and the effects observed by XRD and FTIR measurements, as well.

Among the Co-containing samples, the $\mathrm{Ca} / \mathrm{P}$ atomic ratios range from 1.6 to 2.0 with a non-linear tendency, in terms of the $\mathrm{Ca} / \mathrm{P}$ atomic ratios, as the content of $\mathrm{Co}$ varies. Besides, the elemental compositions of $\mathrm{Ca}, \mathrm{P}$, and $\mathrm{O}$ elements are $16.6,8.4,30.7 \%$ for spent $\mathrm{CoCa} 1 \mathrm{H}$ (Table 2), which ascertains the increased $\mathrm{Ca} / \mathrm{P}$ ratio of after the catalytic test. When compared with $\mathrm{CoCa} 06 \mathrm{H}$ and $\mathrm{CoCa} 04 \mathrm{H}$ samples, the amounts of $\mathrm{Ca}$ on the surface increase for the former samples being indicative of the $\mathrm{Ca}$ ions migration from the structure to the surface. 
Regarding $\mathrm{NiCa} 1 \mathrm{H}$, the surface $\mathrm{Ca} / \mathrm{P}$ atomic ratio is of ca 2.5 (Table 2), which is considerably higher than the other samples. This means that the sample contains mainly Ca ions on the external surface of the solid in a huge amount of ca. $57.1 \%$, which is less prone to improve the activity due to the few acid sites available for the reaction. Another important fact is that the absence of $\mathrm{C}$ on the solid surface, along with the negligible $\mathrm{Ni}$ contents in the sample, suggests that the sample has a poor performance in the EG reaction. This is because of the insufficient amount of $\mathrm{Ni}$ after the reaction and the $\mathrm{Ni}$ inability to promote esterification reactions, as well.

Notably, the SEM micrographs of the solids after recyclability studies show that the morphology of $\mathrm{CuCa} 1 \mathrm{H}$ is also identical to those of the fresh ones, showing no noticeable changes in the 5th cycle of the EG reaction (Figure 10). On the contrary, changes in the morphologies of $\mathrm{CuCa} 06 \mathrm{H}$ and $\mathrm{CoCa} 1 \mathrm{H}$ for clusters confirm the densification the particle aggregates and active phase loss during the EG reaction, and all of these factors cause the solid deactivation. Accordingly, the BET surface areas of the spent samples are 3 and $12 \mathrm{~m}^{2} \mathrm{~g}^{-1}$ for $\mathrm{CoCa} 1 \mathrm{H}$ and $\mathrm{CuCa} 06 \mathrm{H}$, respectively. This is due to the aggregates/clusters formation in these samples containing high amounts of copper. In contrast, high amounts of $\mathrm{Cu}$ incorporated into HAPs hold the highest BET surface area of ca. $27 \mathrm{~m}^{2} \mathrm{~g}^{-1}$ due to dispersion of $\mathrm{Cu}$ species already existing on the solid surface of the $\mathrm{CuCa} 1 \mathrm{H}$.

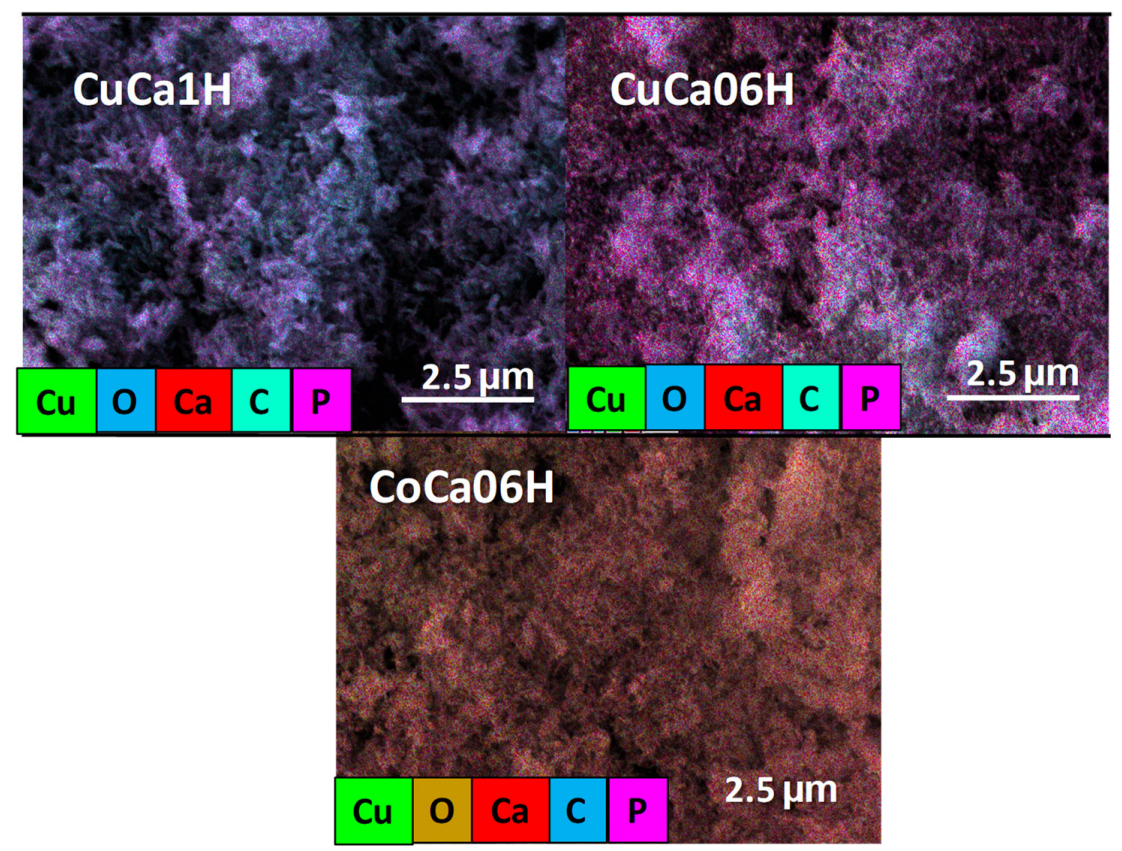

Figure 10. EDS elemental mappings of the spent $\mathrm{CuCa} 1 \mathrm{H}$ and $\mathrm{CuCa} 06 \mathrm{H}$ (after the 5th cycle), and CoCa1H (after the 3rd cycle). Reaction conditions: $75 \mathrm{mg}$ of catalyst, glycerol to acetic acid molar ratio of 0.25 , and reaction temperature of $80^{\circ} \mathrm{C}$.

Moreover, energy dispersive X-ray elemental mapping micrograph ensures the stability of the HAP structure for spent $\mathrm{CuCa} 1 \mathrm{H}$ and the homogeneous distribution of $\mathrm{C}$ and $\mathrm{Cu}$ elements on the solid surface. On the contrary, the distribution of $\mathrm{C}$ almost covers the whole area of the EDS mapping for $\mathrm{CoCa} 1 \mathrm{H}$ and $\mathrm{CuCa} 06 \mathrm{H}$, as opposed to that of $\mathrm{CuCa} 1 \mathrm{H}$. Thereby, the loss of activity in the cases of $\mathrm{CoCa} 1 \mathrm{H}$ and $\mathrm{CuCaO6H}$ is accountable to the leaching of $\mathrm{Cu}$ and $\mathrm{Co}$ species and adsorbed carbon coverage of the solids surfaces, as well. Consequently, carbon species adsorption from both reaction products and oligomers may block the active sites of these samples, probably provoking the activity loss over these solids (Figure 6). Obviously, the change in the morphology is unlikely in $\mathrm{CuCa} 1 \mathrm{H}$ due to its structural stability and, thus, good catalytic performance of the solid mainly arising from high $\mathrm{Cu}$ content into the HAP structure. 
Based on the above observations, the Co-containing HAPs having lower acidity compared to that of $\mathrm{Cu}$-based one show low performance in the EG reaction. In addition, the Co contents on the solid surface are much lower than those of the bulk solids, e.g., 2.3 to $16 \mathrm{wt} . \%$, which is indicative of Co active species are exposed on the external surface of the solids in lesser amount, after the catalytic tests. This contributes for the poor performances of the solids in the EG reaction. The occurrence of a slight increment of $\mathrm{C}$ on $\mathrm{CoCaO6H}$ and $\mathrm{CoCa} 04 \mathrm{H}$ surfaces may, thus, be interpreted as strong adsorption of oligomers, independently of the $\mathrm{Ca} / \mathrm{Co}$ ratios.

Additionally, the chemical analyses by ICP-OES of the filtrate, obtained on separating the $\mathrm{CuCa} 1 \mathrm{H}$ catalyst, indicate only $2 \%$ of $\mathrm{Cu}$, while that of $\mathrm{CuCaO6H}$ is $6 \%$ at the end of the 5th run. As shown in Figure 6, the glycerol conversion decreases marginally from 54 to 38\% over $\mathrm{CuCa} 1 \mathrm{H}$, being more pronounced during the fifth cycle of $\mathrm{CuCa} 06 \mathrm{H}$.

This correlates with the deactivation of the latter solid in consequence of the $\mathrm{Cu}$ leaching during the reaction, in contrast to the good catalytic performance achieved by $\mathrm{CuCa} 1 \mathrm{H}$. In the case of spent $\mathrm{CoCa} 1 \mathrm{H}$, the filtrate has $12 \%$ of $\mathrm{Co}$ after the 3 rd cycle, which is close to that found in the bulk fresh solid. Such bad performance is due to almost all Co loss, after three cycles of these experiments in $\mathrm{CoCa} 1 \mathrm{H}$, as stated before.

\subsubsection{Valence States and Surface Properties}

Valence states of the elements present in the spent samples and their surface compositions are investigated by Electron Paramagnetic Spectroscopy (EPR). Literature reports that the EPR signal of pure HAPs is silent $[37,38]$. Therefore, the incorporation of paramagnetic $\mathrm{Co}^{2+}, \mathrm{Ni}^{2+}$, or $\mathrm{Cu}^{2+}$ ions into HAP lattice can lead to a deeper understanding of the crystal symmetry for metal valences and their chemical environments, as found in metal-containing solids $[39,40]$. EPR spectra of the spent catalysts depict broad asymmetric signals, owing to the isolated $\mathrm{Co}^{2+}, \mathrm{Ni}^{2+}$, or $\mathrm{Cu}^{2+}$, or even $\mathrm{PO}_{4}{ }^{2-}$ and $\mathrm{O}^{2-}$ ions (Figure 11).

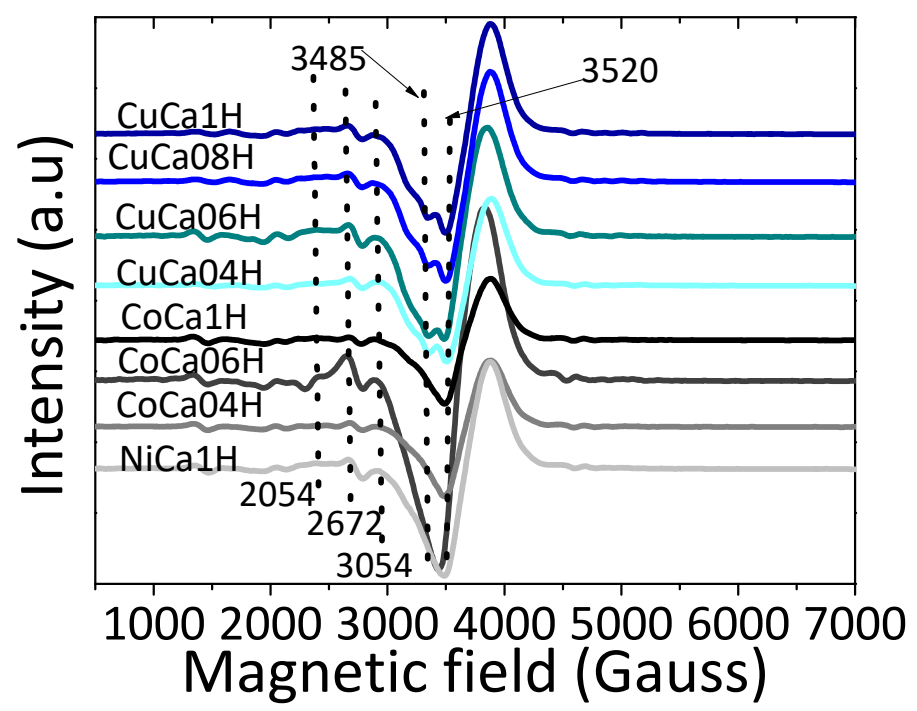

Figure 11. EPR spectra of the spent catalysts. The samples are evaluated in the EG reaction at $80{ }^{\circ} \mathrm{C}$ and glycerol to acetic acid molar ratio of 0.25 .

Although the EPR spectra have similar features in the magnetic field range of 20004000 Gauss measured at room temperature, some aspects distinguish the solids. The spent catalysts disclose broad EPR signals with typical asymmetric doublets at about 3485 and 3520 Gauss. As known, these signal positions are in accordance with g values of 1.980 and 2.003, which may correlate to either $\mathrm{PO}_{4}$ or OH species [40-43].

For $\mathrm{Cu}$-containing HAPs, the spectra have four splitting features besides the main signal. The appearance of the humps in the magnetic field values in the 2500-2800 Gauss range is correlated to the $\mathrm{g} / \mathrm{/}$ value of 2.390 assigning to be from the splitting hyperfine 
interactions typical of isolated $\mathrm{Cu}^{2+}$ cations, as observed in $\mathrm{Cu}$-containing mesoporous materials [43]. Accordingly, other studies mention the behavior of $\mathrm{Cu}$ species in the form of $\mathrm{CuO}$ having g value of 2.193, along with signals other than those of $\mathrm{g} 1=2.470, \mathrm{~g} 2=2.167$, and $\mathrm{g} 3=2: 088$, for well dispersed framework $\mathrm{Cu}$ species with anisotropic coordination environments [42-44]. Concurrently, $\mathrm{Cu}^{+}$species are silent in the EPR spectra [42,43]; thus, $\mathrm{Cu}^{2+}$ sites in the HAP lattice and isolated $\mathrm{Cu}^{2+}$ are observed by the EPR measurements. It is quite interesting to note that the signals of $\mathrm{Cu}$ can be occasionally overlapped with those of the defects of HAPs, such as vacant $\mathrm{OH}$ and $\mathrm{CO}_{2}{ }^{-}$species, as well.

It could indicate that both isolated $\mathrm{Cu}^{2+}$ and $\mathrm{Cu}^{1+}$ present in the HAPs matrix are the active sites of the catalysts. When $\mathrm{Cu}^{2+}$ ions, e.g., atomic radius $73 \mathrm{pm}$, replace $\mathrm{Ca}^{2+}$ ones, e.g., atomic radius $100 \mathrm{pm}$, in the hydroxyapatite host lattices, local distortions may take place owing to the mismatch of the bigger size of $\mathrm{Ca}^{2+}$ ions, compared to that of $\mathrm{Cu}^{2+}$ ones. Similar effects can be also observed for $\mathrm{Ni}^{2+}$, e.g., atomic radius $73 \mathrm{pm}$ or $\mathrm{Co}^{2+}$, e.g., atomic radius 79 pm substitution by $\mathrm{Ca}^{2+}$ ions, which permits $\mathrm{Co}^{2+}$ and $\mathrm{Ni}^{2+}$ ions to diffuse easier than $\mathrm{Ca}^{2+}$ ions into the HAP lattice.

These local distortions do not affect the coordination environment of isolated $\mathrm{Cu}^{2+}$ in the form of copper clusters, that may be a result of the agglomeration of the particles observed by SEM-EDS and chemical analyses results, after the catalytic test. Additionally, the intensity of the signal increases as the copper amounts increases because of a probable dipole interaction between neighboring paramagnetic species. Therefore, at high copper contents, aggregation of $\mathrm{Cu}$ species, as well as the reduction of $\mathrm{CuO}$ to $\mathrm{Cu}_{2} \mathrm{O}$, might be occurred during the catalytic tests. One possible reason is that EPR signal is insensitive to $\mathrm{CuO}_{\mathrm{x}}$ clusters in samples with $\mathrm{Cu}$ contents more than $9.0 \%$; therefore, some of the $\mathrm{Cu}$ species may be leached during the catalytic tests. Therefore, these $\mathrm{CuO}_{x}$ clusters may be responsible for helping the catalytic performance of $\mathrm{CuCa} 1 \mathrm{H}$ and $\mathrm{CuCa06H}$ solids, along with the structural $\mathrm{Cu}$ sites in the HAPs.

For all the Co-containing HAPs catalysts, the EPR signals are detected at around 2000 and 4500 Gauss in a similar fashion as those of $\mathrm{Cu}$-containing HAPs. The EPR signals of $\mathrm{CoCa06H}$ and $\mathrm{CaCo} 4 \mathrm{H}$ samples possessing low cobalt contents are more intense than one of $\mathrm{CuCa} 1 \mathrm{H}$, indicating that more Co species existed on the surface of the former spent solids. Additionally, the signal of $\mathrm{CoCa} 1 \mathrm{H}$ is much narrower than the ones of $\mathrm{CuCa} 1 \mathrm{H}$ and $\mathrm{NiCa} 1 \mathrm{H}$, which is in accordance with literature reports for local atomic distortions, electronic structure of Co in the HAPs, and interaction mechanisms between spins, as well. These results assign to the existence of $\mathrm{Co}^{2+}$ species pertaining to both tetrahedral and octahedral coordination, respectively, in all samples [45,46]. Moreover, EPR signal for $\mathrm{Co}^{2+}$ has $\mathrm{g}$ value of 2.120 being superimposed by other broad anisotropic signals with $g \perp \approx 5.80-5.44$ and $g|| \approx 2.00[45,46]$. This is indicative of the fact that Co exists in the HAP lattice as divalent cobalt, and these species contributes to some extend to the catalytic performance of the solid, at high Co contents. In contrast, other characterization techniques demonstrate that Co is leached from the solids at low Co contents, which is indeed the leading cause of the solids' deactivation.

It can be seen that the EPR signal of $\mathrm{NiCa} 1 \mathrm{H}$ is much weaker and narrower than that of $\mathrm{CuCa} 1 \mathrm{H}$. Such signal is broadened out by the strong spin-spin interaction of Ni presence, when compared with that of CoCa1H. Literature reports illustrates that EPR signal of nickel appears as anisotropic broad signal, while splitting occurs, being characteristic of $\mathrm{Ni}^{2+}$ with g value within 2.281-2.293 [47,48]. Moreover, EPR spectrum of NiCa1H shows a similar occurrence of the signal and nickel is still present as $\mathrm{Ni}^{2+}$ predominantly well dispersed in the HAP lattice. On the other hand, the EPR signal also suggests the NiO presence as a result of Ni leaching out of HAP lattice during the catalytic run, being preferable on solid surface, as demonstrated by EDS results. Thus, it is difficult to assess the role of Ni for the catalytic performance of the $\mathrm{NiCa} 1 \mathrm{H}$ catalyst in the glycerol esterification, separately. It seems plausible that the solid deactivate during the runs and the Ni leaching might contribute to the bad performance of the solid in the reaction. 
To clarify the valence states of the elements on solid surface and their concentrations, XPS analyses are carried out for $\mathrm{CuCa} 1 \mathrm{H}, \mathrm{NiCa} 1 \mathrm{H}$, and $\mathrm{CoCa} 1 \mathrm{H}$ recycled catalysts. These three samples are selected because the corresponding catalysts undergo different behavior with respect to recycling experiments. The XPS survey scans indicates the presence of $C, O$, $\mathrm{Ca}, \mathrm{Ni}, \mathrm{Co}$, and $\mathrm{Cu}$ in all solids. Besides the expected elements, traces of $\mathrm{Cl}$ and $\mathrm{Na}$ are also found arising from impurities. In addition, the binding energy values and compositions of surface species are listed in Table 3.

Table 3. Binding Energies values (eV) of the C $1 s, \mathrm{Ca} 2 p_{3 / 2}, \mathrm{O} 1 s, \mathrm{P} 2 p, \mathrm{Cu} 2 p_{3 / 2}$, and Ni $2 p_{3 / 2}$ core levels for the spent catalysts tested after recycling experiments.

\begin{tabular}{|c|c|c|c|c|c|c|c|}
\hline Catalysts & $\mathrm{C} 1 \mathrm{~s}$ & O 1s & Ca $2 p_{3 / 2}$ & P 2p & Co $2 p_{3 / 2}$ & $\mathrm{Ni} 2 p_{3 / 2}$ & $\mathrm{Cu} 2 p$ \\
\hline \multirow{2}{*}{ CoCa1H } & 284.6 & 531.1 & 347.1 & \multirow{2}{*}{133.3} & 781.5 & & \\
\hline & 286.2 & 533.0 & 353.6 & & 796.3 & & \\
\hline \multirow{4}{*}{$\mathrm{NiCa1H}$} & 288.0 & \multirow{4}{*}{531.2} & & \multirow{4}{*}{133.3} & & & \\
\hline & 282.5 & & 347.3 & & & 856.6 & \\
\hline & 285.1 & & 353.5 & & & 873.4 & \\
\hline & 288.9 & & & & & & \\
\hline \multirow{4}{*}{ CuCa1H } & 284.6 & & & \multirow{4}{*}{133.0} & & & 932.7 \\
\hline & 286.2 & 530.8 & 346.8 & & & & 935.4 \\
\hline & 2881 & 532.7 & 353.8 & & & & 940.2 \\
\hline & & & & & & & 943.4 \\
\hline
\end{tabular}

It should be noted that the binding energy values of the Ca $2 p$ core levels split into two contributions at around 346.7 and $353.8 \mathrm{eV}$ coming from the doublet Ca $2 p_{3 / 2}$ and $\mathrm{Ca} 2 p_{1 / 2}$, respectively. This assigns the existence of $\mathrm{Ca}^{2+}$ in all samples from HAP structure $[28,49,50]$. In agreement, the phosphorous species in $\mathrm{P}^{5+}$ state on the catalyst surface is identified by the binding energy value located at 133.0-133.3 eV for all the spent catalysts [49,50]. Moreover, the surface $\mathrm{Ca} / \mathrm{P}$ ratio is found to be 1.20, 1.31, and 1.10, respectively, for $\mathrm{CuCa} 1 \mathrm{H}, \mathrm{NiCa} 1 \mathrm{H}$, and $\mathrm{CoCu} 1 \mathrm{H}$ spent solids, instead of the bulk value of 1.67. In addition, the $\mathrm{Ca} / \mathrm{O}$ surface atomic ratios are $0.27,0.26$, and 0.25 for $\mathrm{CuCa} 1 \mathrm{H}, \mathrm{NiCa} 1 \mathrm{H}$, and $\mathrm{CoCu} 1 \mathrm{H}$ spent solids, respectively. Thus, the values of $\mathrm{Ca} / \mathrm{P}$ and $\mathrm{Ca} / \mathrm{O}$ surface atomic ratios are in the $1-10 \%$ range compared with bulk values. The obtained results are within the XPS technique limits of the accuracy.

Furthermore, XPS data clearly show the concision of previous elemental analyses and the hexagonal structure of HAP described by XRD and FTIR results. Accordingly, the well-known HAP structure is built by the columns having $\mathrm{Ca}$ ions and $\mathrm{O}$ atoms, where these columns are in parallel to the hexagonal axis [51]. It is reported that these divalent calcium ions in the lattice are exchangeable by $\mathrm{OH}^{-}$and $\mathrm{PO}_{4}{ }^{3-}$ ions and other divalent cations, such as $\mathrm{Cu}$, that form the HAP structures [18,51].

The XPS spectrum of $\mathrm{Cu} 2 p_{3 / 2}$ core level for $\mathrm{CuCa} 1 \mathrm{H}$ (Figure 12a) shows four deconvoluted peaks at around 932.7, 935.4, 940.2, and 943.4 eV. The peaks located at 932.7 and $935.4 \mathrm{eV}$ represent the main $\mathrm{Cu} 2 p_{3 / 2}$ peak, these contributions are assigned to the presence of $\mathrm{Cu}^{+}$and the $\mathrm{Cu}^{2+}$ species, respectively, $[27,28,51]$. In addition, the shake-up satellites peaks are visible at 940.2 and $943.4 \mathrm{eV}$, corresponding to the existence of $\mathrm{Cu}^{2+}$ on the surface. If we consider the relative intensity of the peak at $932.7 \mathrm{eV}$, assigned to $\mathrm{Cu}^{+}$ and that of the contributions at 935.4, 940.2, and $943.4 \mathrm{eV}$, assigned to $\mathrm{Cu}^{2+}$, we have a more or less similar percentage of $\mathrm{Cu}^{+}$and $\mathrm{Cu}^{2+}$. This is partially confirmed by the EPR measurements and implies in the presence of $\mathrm{Cu}^{2+}$ on the HAP surface arising from $\mathrm{Cu}^{2+}$ included in the hydroxyapatite lattice and isolated $\mathrm{Cu}_{2} \mathrm{O}$ species (from XRD results), as well. The total surface amount of $\mathrm{Cu}$ on surface in $\mathrm{CuCa} 1 \mathrm{H}$ is roughly 6.07 in weight $\%$, which means that, in addition to $\mathrm{Cu}^{2+}$ species into the HAP lattice, there is $\mathrm{Cu}_{2} \mathrm{O}$, hardly detected in the bulk $\mathrm{Cu}$ (content of ca. $17.0 \%$ is lesser than that of the surface one). Due to the XPS sensitivity, the obtained surface percentage is acceptable and confirms the resistance against leaching of the $\mathrm{CuCa} 1 \mathrm{H}$ catalyst. 


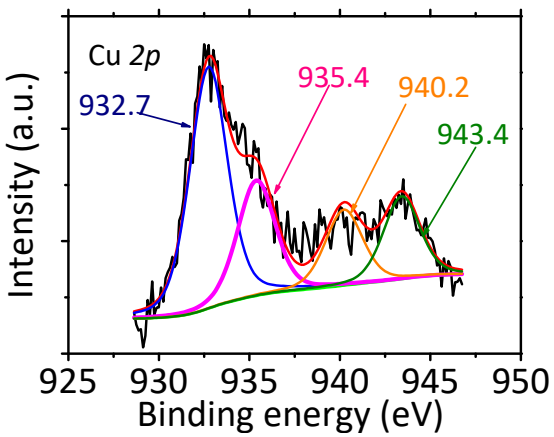

(a)

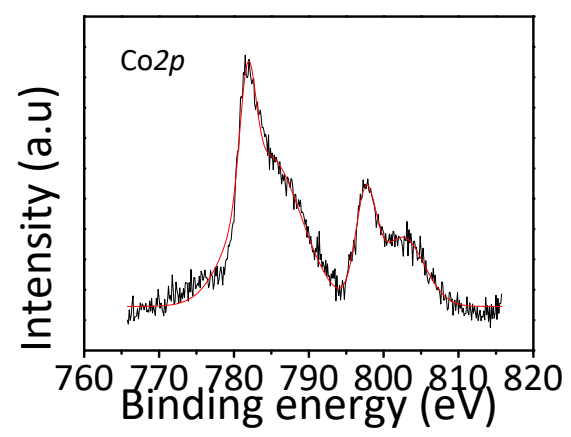

(b)

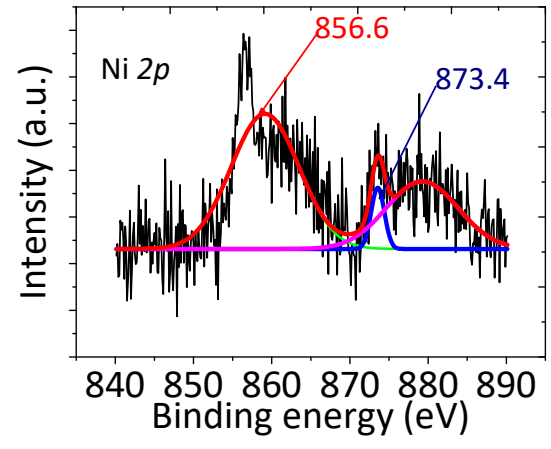

(c)

Figure 12. XPS spectra of the $\mathrm{Cu} 2 p, \mathrm{Ni} 2 p$, and Co $2 p$ core levels, respectively, for (a) CuCa1H after the 5 th cycle, (b) $\mathrm{CoCu} 1 \mathrm{H}$ after the 3 rd cycle, and (c) $\mathrm{NiCa} 1 \mathrm{H}$ after $6 \mathrm{~h}$ of reaction. Reaction conditions: $75 \mathrm{mg}$ of catalyst, glycerol to acetic acid molar ratio of 0.25 and reaction temperature of $80^{\circ} \mathrm{C}$.

As found elsewhere [51], the high energy satellite of the doublet $\mathrm{Cu} 2 p_{1 / 2}$ is usually overlapped by Ca LMM Auger resonance peaks, however, although the X-ray Cu LMM Auger lines are very noisy, which proved that relevant presence of $\mathrm{Cu}^{+}$species on $\mathrm{CuCa}$ 1H. Furthermore, $\mathrm{O} 1 \mathrm{~s}$ core level has two components at binding energies values of 530.8 and $532.7 \mathrm{eV}$. The major contribution at $530.8 \mathrm{eV}$ is ascribable to $\mathrm{O}^{2-}$ in the lattice oxide, whereas $\mathrm{OH}$ groups and surface-adsorbed oxygen are detected at $532.7 \mathrm{eV}[28,39,40]$. The latter species can be a result of the glycerol and acetin and oligomers adsorbed products from the reaction, as suggested by FTIR spectra.

The C 1s XPS spectrum for CuCa1H (Figure 13a) exhibits three deconvoluted peaks at binding energies values of 284.6, 286.2, and $288.1 \mathrm{eV}$ for all samples, indicating that the surface adsorbed carbon species are of the same nature on catalyst surfaces. The first contribution accounts for the majority of carbon species at about $284.6 \mathrm{eV}$, which is typical of adventitious organic carbon. In addition, peak position at $284.6 \mathrm{eV}$ is similar to that of the contributions assigned to the from $\mathrm{C}-\mathrm{C}$ bonds. Moreover, the minor contributions at 286.2 and $288.1 \mathrm{eV}$ are due to the $\mathrm{C}-\mathrm{O} / \mathrm{OH}$ and $\mathrm{C}=\mathrm{O}$ bonds, respectively [23]. These results agree with those of FTIR spectra of the solids that demonstrate the $\mathrm{C}-\mathrm{C}$ vibrations oxygenated functional groups, such as carboxyl, hydroxyl, and carbonyl groups, from the adsorbed glycerol, acetins, and oligomers. The carbon contribution on $\mathrm{CuCa} 1 \mathrm{H}$ accounts for 9.21 in weight $\%$ of the elements present on surface confirming the resistance against active site block by carbon species adsorption on solid surface. This result confirms the best performance of the $\mathrm{CuCa} 1 \mathrm{H}$ in EG reaction.

The Co $2 p$ core level spectrum for CoCa1H spent sample is depicted in Figure 12b. The spectrum shows peaks in a doublet, which arises from spin-orbit coupling Co $2 p_{3 / 2}$-Co $2 p_{1 / 2}$. The binding energies of $\mathrm{Co}_{2} 2 p_{3 / 2}$ and $\mathrm{Co}_{2} 2 p_{3 / 2}$ peaks are at about 781.5 and $796.0 \mathrm{eV}$, respectively, which prove clearly that cobalt is present mainly as $\mathrm{Co}^{2+}$ ions. This is in accordance with XPS data for Co-containing HAPs found elsewhere [51]. The satellites shake up structure in high-spin $\mathrm{Co}^{2+}$ is also seen in the spectrum, which derived from $\mathrm{Co}^{2+}$ species. In agreement, the presence of satellite in Co-based catalysts suggest that the $\mathrm{Co}^{2+}$ may be attached to hydroxyl groups from $\mathrm{Co}-\mathrm{OH}$ species $[39,52,53]$, being in accordance with FTIR results.

In line with these assumptions, $\mathrm{O} 1$ s peaks of $\mathrm{CoCa} 1 \mathrm{H}$ are located at 531.1 and $533.0 \mathrm{eV}$, truly confirming the presence of the lattice oxygen oxide and $\mathrm{OH}$ groups plus surfaceadsorbed oxygen species. When compared the binding energies values for $\mathrm{O} 1 \mathrm{~s}$ of $\mathrm{CoCa} 1 \mathrm{H}$ with those of $\mathrm{CuCa} 1 \mathrm{H}$, one can see a slight shift towards the low binding energies in the former sample. This can be interpreted as $\mathrm{Co}$ is strongly interacting with $\mathrm{OH}$ groups from $\mathrm{H}_{2} \mathrm{O}$ or glycerol from the reaction to from $\mathrm{Co}-\mathrm{OH}$ group on the surface of catalyst. Based on previous reports [18,52], Lewis basic sites, such as $\mathrm{O}^{2-}$ from $\mathrm{PO}_{3}{ }^{4-}$ chemical entities, as well as vacancies acidic sites, e.g., $\mathrm{Ca}^{2+}$ or $\mathrm{OH}^{-}$, can be detected by on solid surface of 
hydroxyapatites. Thus, the Lewis acid sites are prone to react with water generated during the EG reaction forming surface $\mathrm{OH}$ groups; hence, these species interact with Co species, which are leached from hydroxyapatite matrix to obtain $\mathrm{Co}-\mathrm{OH}$ species. As consequence, the catalytic activity of the solid is restricted to the third use in the reaction. Furthermore, the amount of cobalt obtained by XPS is 4.52 in weight \%, which is in accordance with the Co leaching from the solid to its surface as observed by EDS analyses.

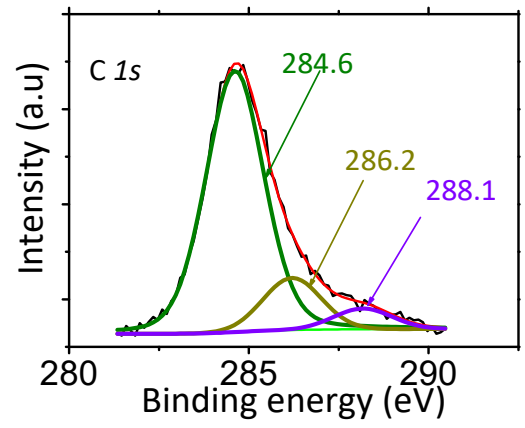

(a)

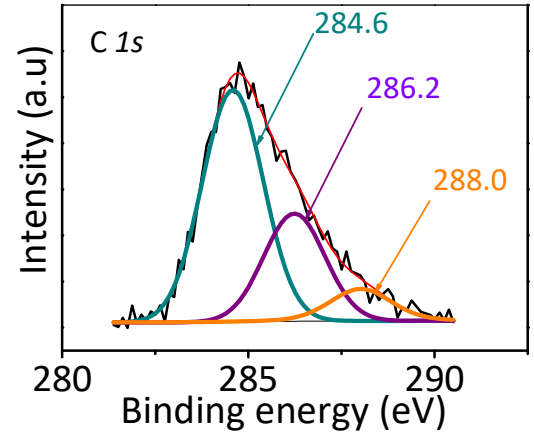

(b)

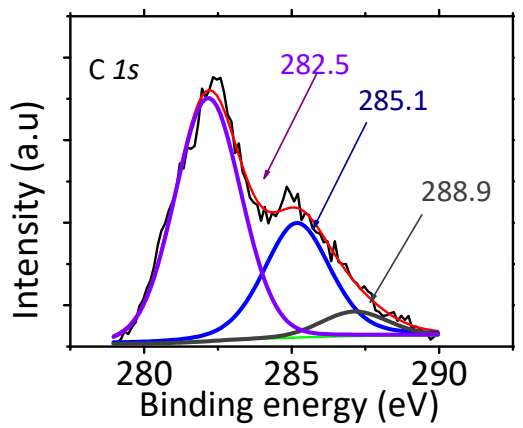

(c)

Figure 13. XPS spectra of the $\mathrm{C} 1$ s for (a) $\mathrm{CuCa} 1 \mathrm{H}$ after the 5th cycle, (b) CoCu1H after the 3rd cycle, and (c) $\mathrm{NiCa} 1 \mathrm{H}$ after $6 \mathrm{~h}$ of reaction. Reaction conditions: $75 \mathrm{mg}$ of catalyst, glycerol to acetic acid molar ratio of 0.25 , and reaction temperature of $80^{\circ} \mathrm{C}$.

Particularly, Figure 13b confirms the existence of the carbon groups on the surface of $\mathrm{CoCa} 1 \mathrm{H}$ through the $\mathrm{C} 1 \mathrm{~s}$ core level, which is almost identical to that of $\mathrm{CuCa} 1 \mathrm{H}$. Indeed, the peaks positions at $284.6,286.2$, and $288.0 \mathrm{eV}$ illustrate the presence of $\mathrm{C}-\mathrm{C}, \mathrm{C}-\mathrm{O} / \mathrm{OH}$, and $\mathrm{C}=\mathrm{O}$ bonds functional groups on the solid surface. The intensity of the peak at $286.2 \mathrm{eV}$ $(\mathrm{C}-\mathrm{O} / \mathrm{OH})$ increased compared to that of $\mathrm{CuCa} 1 \mathrm{H}$; hence, this change in intensity can prove that there is more $\mathrm{OH}$ from $\mathrm{Co}-\mathrm{OH}$ leached species than in $\mathrm{CuCa} 1 \mathrm{H}$. Another fact that explains the deactivation of the solid is in part due to the elevated carbon content on its surface 5.85 in weight \%, which was consistent with previous EDS and FTIR results.

XPS spectrum for $\mathrm{Ni} 2 p_{3 / 2}$ and $2 p_{1 / 2}$ core levels of spent $\mathrm{NiCa} 1 \mathrm{H}$ catalyst is shown in Figure 12c. The peaks located at 856.6 and $873.4 \mathrm{eV}$ are associated with the binding energies of Ni $2 p_{3 / 2}$ and $2 p_{1 / 2}$ core levels, as observed for hydroxyapatite-based solids [54]. These peaks are coupled with shake up satellite ones at about $861.3 \mathrm{eV}$ and spin-orbit energy gaps, which meant that mainly existed as $\mathrm{Ni}^{2+}$ on the solid surface. Important is to note that the $\mathrm{Ni} 2 p_{3 / 2}$ binding energy for $\mathrm{Ni}^{2+}$ in the form of $\mathrm{NiOOH}$ is also detected by the binding energy of $861.2 \mathrm{eV}[39,55]$, which is indeed in position close to those of the satellites. Thus, $\mathrm{Ni}$ is likely leached from HAP lattice to form extraframework $\mathrm{Ni}^{2+}$ as $\mathrm{NiOOH}$. The $\mathrm{O} 1 s$ binding energy of $531.2 \mathrm{eV}$ for $\mathrm{NiCa} 1 \mathrm{H}$ ascertains these results as it confirms the presence of $\mathrm{O}^{2-}$ in lattice oxide, probably coming from $\mathrm{NiOOH}$ species. Consistent with these assumptions, $\mathrm{Ni}^{2+}$ species can be present in two different environments in HAPs, such as $\mathrm{P}-\mathrm{O}-\mathrm{Ni}-\mathrm{O}-\mathrm{P}$ and $\mathrm{HO}-\mathrm{Ni}-\mathrm{O}-\mathrm{P}$, both arising from the ion exchange in the two sites $\mathrm{Ca}$ (I) and $\mathrm{Ca}$ (II) [53]. The amount of Ni on solid surface is 1.9 in weight $\%$.

$\mathrm{C} 1 s \mathrm{XPS}$ spectrum of $\mathrm{NiCa1H}$ (Figure 13c) depicts three deconvoluted peaks in similar fashion of those of $\mathrm{CuCa} 1 \mathrm{H}$ and $\mathrm{CoCa} 1 \mathrm{HC} 1 \mathrm{~s}$ spectra. It could be interpreted from Figure 13 that the peaks at $282.5,285.1$, and $288.9 \mathrm{eV}$ are assigned to be from carbide, $\mathrm{C}-\mathrm{C}, \mathrm{C}=\mathrm{C}$, and $\mathrm{C}=\mathrm{O}$ groups, respectively [39]. All of these groups arise from the adsorption of glycerol, oligomers, and acetin products on solid surface after $6 \mathrm{~h}$ of recycling experiments and a relevant amount of carbide. It is worthy of note that the intensity of the peak $285.1 \mathrm{eV}$ greatly increased comparatively with those of $\mathrm{CuCa} 1 \mathrm{H}$ and $\mathrm{CoCa} 1 \mathrm{H}$, which is possibly due to the $\mathrm{C}=\mathrm{C}$ bonds compounds increment from oligomers on $\mathrm{Ni}^{2+}$ sites. It is worth noting that the carbon on surface still remained on considerable amounts of ca. $10.97 \%$ in weight, being the highest among the samples studied. The latter may imply in a strong adsorption of large carbon species that can result in active sites blockage of the $\mathrm{NiCa} 1 \mathrm{H}$, along with 
nickel leaching from HAP lattice, all of these factors being the most possible cause of the bad performance of the solid in the EG reaction.

The spent characterization results show that the clear the reason for the best performance of the of $\mathrm{CuCa} 1 \mathrm{H}$ possessing high contents of $\mathrm{Cu}$ of ca. $17.0 \%$ is the presence of $\mathrm{Cu}$ sites onto the hydroxyapatite matrix and extraframework $\mathrm{Cu}^{2+}$ species, as well. On the contrary, $\mathrm{Co}^{2+}$ and $\mathrm{Ni}^{2+}$ leaching from HAPs lattice during the catalytic runs and oligomeric carbon adsorption by the aforesaid cations lead to $\mathrm{CoCa} 1 \mathrm{H}$ and $\mathrm{NiCa} 1 \mathrm{H}$ catalyst deactivation.

\section{Materials and Methods}

\subsection{Materials}

Ammonium phosphate $\left.\left(\mathrm{NH}_{4}\right)_{2} \mathrm{HPO}_{4}\right)$, calcium chloride $\mathrm{CaCl}_{2} \cdot 2 \mathrm{H}_{2} \mathrm{O}$, copper (II) nitrate hexahydrate $\left(\mathrm{Cu}\left(\mathrm{NO}_{3}\right)_{2} \cdot 6 \mathrm{H}_{2} \mathrm{O}\right.$, cobalt(III) nitrate $\left(\mathrm{Co}\left(\mathrm{NO}_{3}\right)_{3}\right)$, nickel(II) nitrate hexahydrate $\left(\mathrm{Ni}\left(\mathrm{NO}_{3}\right)_{2} \cdot 6 \mathrm{H}_{2} \mathrm{O}\right)$ salts, and aqueous ammonium solution were purchased from Vetec (Vetec, São Paulo, Brazil). Commercial copper-containing nanotubes were acquired from Sigma Aldrich. All reactants have a maximum purity level available and were used without further purification.

\subsection{Synthesis of the Hydroxyapatites}

Hydroxyapatites were synthesized through co-precipitation using the methods described in the literature [18]. First, $300 \mathrm{~mL}$ of $0.10 \mathrm{~mol} \mathrm{dm}^{-3}$ ammonium phosphate solution was submitted to reflux at $100{ }^{\circ} \mathrm{C}$ during $30 \mathrm{~min}$ and then cooled to room temperature. Afterwards, $500 \mathrm{~mL}$ of an aqueous equimolar calcium chloride solution was slowly added to the previous solution, along with a $25 \%$ aqueous ammonium solution, under continuous stirring. Subsequently, the reaction mixture was heated at $100^{\circ} \mathrm{C}$ for $1 \mathrm{~h}$ to form a suspension. Then, the $\mathrm{pH}$ of the aforesaid suspension was adjusted to 10.5 using aqueous ammonium and later kept at $24 \mathrm{~h}$ under at room temperature. After this period, the solution was left to attain $25^{\circ} \mathrm{C}$ with the subsequent filtration by vacuum and washing repeatedly with water till a negative test for chloride ions. The dried gel thus obtained was dried at $100{ }^{\circ} \mathrm{C}$ overnight. After recovering the powdery products, the hydroxyapatites were finally calcined under air flow at $550^{\circ} \mathrm{C}$ for $2 \mathrm{~h}$. The sample was denoted as $\mathrm{CaH}$. This sample is a calcium deficient hydroxyapatite with $\mathrm{Ca} / \mathrm{P}=1.29$ [18].

The synthesis of the copper-containing $\mathrm{CaH}$ series of solids followed a similar procedure with the aim to have a $(\mathrm{Cu}+\mathrm{Ca}) / \mathrm{P}$ ratio of 1 . Specifically, a $100 \mathrm{~mL}$ of a $0.50 \mathrm{~mol} \mathrm{dm}{ }^{-3}$ aqueous ammonium phosphate solution was refluxed at $100{ }^{\circ} \mathrm{C}$ for $1 \mathrm{~h}$ and then being cooled under continuous stirring. Subsequently, a certain amount of a $0.10 \mathrm{~mol} \mathrm{dm}^{-3}$ aqueous solutions of calcium chloride and copper nitrate was added dropwise to the previous solution, and stirring was continued for additional $30 \mathrm{~min}$. Afterward, the $\mathrm{pH}$ was adjusted to 10.5 with aqueous ammonium solution to obtain a bluish precipitate with reflux while stirring. The obtained gel was then refluxed at $100{ }^{\circ} \mathrm{C}$ and subsequently cooled for aging at the room temperature for $24 \mathrm{~h}$. Finally, the precipitate was filtered washed, and dried in an oven overnight. The calcination was performed under air at $550{ }^{\circ} \mathrm{C}$ for $2 \mathrm{~h}$ with the obtained sample denoted generically as $\mathrm{CuCa} 1 \mathrm{H}$. In this case, the sample has $\mathrm{Cu} / \mathrm{Ca}$ ratio of ca. 1.0 (Table 4). The corresponding $\mathrm{CuCa} 08 \mathrm{H}, \mathrm{CaCuCa06H}$, and $\mathrm{CuCu} 04 \mathrm{H}$ samples were prepared with the same methodology as $\mathrm{CuCa}$ 1H with $\mathrm{Cu}$ to $\mathrm{Ca}$ ratios close to 0.08 , 0.6 , and 0.4 , respectively.

For synthesizing cobalt-containing hydroxyapatites, a similar procedure was followed. Briefly, a $100 \mathrm{~mL}$ of ammonium phosphate solution possessing a concentration of $0.50 \mathrm{~mol} \mathrm{dm}^{-3}$ was refluxed under stirring. After that, a required amount of equimolar aqueous solutions of calcium chloride and cobalt nitrate solutions were added dropwise to the previous solution at $100{ }^{\circ} \mathrm{C}$ for $24 \mathrm{~h}$. Next, the mixture was submitted to aging step, afterwards being filtered, washed, dried, and calcined under air at $550{ }^{\circ} \mathrm{C}$ for $2 \mathrm{~h}$. The $(\mathrm{Co}+\mathrm{Ca}) / \mathrm{P}$ ratio of 1 was obtained with the sample labeled as $\mathrm{CoCa} 1 \mathrm{H}$. Variations of the 
Co content to have $\mathrm{Co} / \mathrm{Ca}$ atomic ratios of $0.08,0.6$, and 0.4 were performed to obtain $\mathrm{CoCa} 08 \mathrm{H}, \mathrm{CoCaCa06H}$, and $\mathrm{CoCa} 04 \mathrm{H}$ samples.

Table 4. Nomenclature and chemical compositions measured by ICP-OES analyses and XRD phases of the fresh solids studied.

\begin{tabular}{|c|c|c|c|c|c|c|c|}
\hline Catalyst & $\begin{array}{c}\mathrm{Cu} / \mathrm{Ca} \\
\text { Atomic } \\
\text { Ratios }\end{array}$ & $\begin{array}{c}\text { Co/Ca } \\
\text { Atomic } \\
\text { Ratios }\end{array}$ & $\begin{array}{c}\mathrm{Ni} / \mathrm{Ca} \\
\text { Atomic } \\
\text { Ratios }\end{array}$ & Cu wt.\% & Co wt.\% & Ni wt.\% & $\begin{array}{c}\text { XRD Phase } \\
\text { [18] }\end{array}$ \\
\hline $\mathrm{CaH}$ & - & - & - & - & - & - & HAP \\
\hline $\mathrm{CuCa} 08 \mathrm{H}$ & 0.08 & - & - & 2.3 & - & - & HAP \\
\hline $\mathrm{CuCa04H}$ & 0.40 & - & - & 9.0 & - & - & HAP \\
\hline $\mathrm{CuCa} 06 \mathrm{H}$ & 0.67 & - & - & 13.3 & - & - & $\begin{array}{l}\text { HAP } \\
\text { HAP }\end{array}$ \\
\hline $\mathrm{CuCa} 1 \mathrm{H}$ & 1.01 & - & - & 17.5 & - & - & $\begin{array}{c}\mathrm{CaHPO}_{4} \\
\mathrm{Cu}_{2}(\mathrm{OH})\left(\mathrm{PO}_{4}\right)\end{array}$ \\
\hline $\mathrm{CoCa} 08 \mathrm{H}$ & - & 0.08 & - & - & 2.5 & - & HAP \\
\hline $\mathrm{CoCa04H}$ & - & 0.38 & - & - & 8.7 & - & HAP \\
\hline $\mathrm{CoCa} 06 \mathrm{H}$ & - & 0.62 & _ & - & 12.5 & - & HAP \\
\hline $\mathrm{CoCa} 1 \mathrm{H}$ & - & 1.07 & & - & 16.2 & - & HAP \\
\hline $\mathrm{NiCa} 1 \mathrm{H}$ & - & - & 1.02 & - & - & 15.7 & HAP \\
\hline CuNB & - & - & - & 17.0 & - & - & $\begin{array}{c}\text { Copper } \\
\text { nanobelts }\end{array}$ \\
\hline
\end{tabular}

Following a typical procedure, a Ni-containing HAP possessing a Ni/Ca ratio of 1.0 was synthesized using ammonium phosphate, calcium chloride, and nickel (II) nitrate salts, together with aqueous ammonium solution. After similar procedures of $\mathrm{CoCa} 1 \mathrm{H}$ and $\mathrm{CuCa} 1 \mathrm{H}$ series of solids, the calcined sample was designed as $\mathrm{NiCa} 1 \mathrm{H}$.

In addition, a commercial copper-containing nanotubes (Sigma Aldrich) having 17.0\% of copper based on nanorods was annealed at $500{ }^{\circ} \mathrm{C}$ for $2 \mathrm{~h}$.

A summary of the description and chemical compositions and phases of the fresh samples is given in Table 4.

The solid, namely CuNB nanobelts, was selected to evaluate its catalytic properties for comparison purposes with those of $\mathrm{Cu}$-containing hydroxyapatites in EG reaction.

\subsection{Characterizations of the Spent Hydroxyapatites}

The X-ray diffraction (XRD) patterns were obtained on a Shimadzu XRD6000 (Shimadzu, Kyoto, Japan) diffractometer with $\mathrm{Cu}-\mathrm{K} \alpha$ radiation at $40 \mathrm{kV}$ and $30 \mathrm{~mA}(\lambda=0.154 \mathrm{~nm})$. The wide-angle measurements were collected at $2 \theta=5-70^{\circ}$. The crystalline phases were identified by comparison with those of Joint Committee on Powder Diffraction reference files.

To examine the contents of the elements, atomic absorption spectroscopy was employed. A GBC 808 AA apparatus was used to determine the $\mathrm{Ca}, \mathrm{Cu}$, and Co content. The chemical analyses phosphorous were conducted in a Shimadzu MultiSpec-1501 spectrophotometer. Before the analyses, the spent solids were dissolved in aqua regia at $90{ }^{\circ} \mathrm{C}$ in a sand bath. Further dilution with deionized water was performed to analyze the actual metals contents.

Nitrogen physisorption isotherms to estimate the specific surface area, pore volume, and pore size distributions were analyzed in the ASAP 2000 Micromeritics equipment (at $-196^{\circ} \mathrm{C}$ Micrometrics, Norcross, GA, USA). The BET specific surface areas were determined from the adsorption branch of the isotherms, while Barret-Joyner-Halenda $(\mathrm{BJH})$ method was used to calculate pore sizes. All spent catalysts were placed inside the sample holder and then heated at $250{ }^{\circ} \mathrm{C}$ under vacuum for $2 \mathrm{~h}$, before recording the analyses.

Fourier transform infrared spectroscopy (FTIR) spectra were recorded in a Bruker equipment (Bruker, Rheinstetten, Germany) between 4000 and $400 \mathrm{~cm}^{-1}$. The self-supporting $\mathrm{KBr}$ disks were prepared upon diluting $1 \mathrm{wt} . \%$ of the samples with $\mathrm{KBr}$, the curves, prior to 
the measurements. In addition, a $4 \mathrm{~cm}^{-1}$ resolution was applied for the spectra recorded FTIR spectra.

Scanning electron microscopy (SEM) analyses are obtained to provide elemental composition and morphology of the solid information. A Quanta-FEG FEI electron microscope (FEI Quanta, Hillsboro, OR, USA) equipment coupled with an EDX Link Analytical QX20000 system coupled to the SEM microscope was used. The acceleration voltage used was of $2 \mathrm{kV}$. Before the analyses, the spent were dispersed in an aluminum sample holder, and sputtering the catalysts with gold was performed.

Electron paramagnetic resonance (EPR) studies were conducted on a Bruker spectrometer (Bruker, Rheinstetten, Germany) to investigate the local environment of the $\mathrm{Cu}$, $\mathrm{Co}$, and $\mathrm{Ni}$ atoms and their valence states. All EPR spectra were recorded at the X-band microwave frequencies close to $9.5 \mathrm{GHz}$. The instrument used for this analysis has a double cavity with high frequency modulation of $100 \mathrm{kHz}$. Samples were placed in quartz tubes of $4 \mathrm{~mm}$ inner diameter at room temperature, prior to the measurements.

X-ray photoelectron spectra (XPS) of the spent catalysts were recorded on a PHI 5700 XPS (Minneapolis, Minnesota USA) in Malaga, Spain. The carbon C 1s core level was energy referenced to adventitious carbon at $285 \mathrm{eV}$. The Multipack software version 9.6.0.15 was used to analyze the XPS spectra. The obtained spectra were fitted using GaussianLorentzian. $\mathrm{Cu} 2 p$ core level spectra were recorded with a low irradiation time (10 $\mathrm{min})$ to avoid the photoreduction of $\mathrm{Cu}^{2+}$ species.

\subsection{Catalytic Tests in Esterification of Glycerol}

The catalytic evaluation of the solids was examined in the esterification of glycerol in the presence of acetic acid using a batch reactor, which consisted of a three-neck flask connected with a reflux condenser and a thermometer. The catalytic tests were carried out loading $75 \mathrm{mg}$ of the catalyst in the closed circulation system, and then acid acetic and glycerol, to obtain a glycerol to the acetic acid molar ratio of 0.25 , were added to the system. The reactants were introduced into the system under continuous stirring. The reaction was operated under atmospheric pressure at $80^{\circ} \mathrm{C}$, initially.

The products were monitored using a Shimadzu gas-chromatography with a capillary column and detected by an FID detector. The aliquots of the liquid products were withdrawing at each $60 \mathrm{~min}$ intervals. The reaction products were analyzed by Intercrom Geração 8000 apparatus, and ortho-xylene used as an internal standard to calculate the glycerol conversion and selectivities.

Different temperature conditions were evaluated. Besides, recycle experiments of the most active solids were carried out at $80{ }^{\circ} \mathrm{C}$ using $75 \mathrm{mg}$ of catalyst and glycerol to the acetic acid molar ratio of 0.25 . The catalyst was stable as a function of the time, throughout experiments lasting up to about $24 \mathrm{~h}$. Thereafter, the catalyst was removed from the reactor, washed and dried to be reused in the reaction. The successive experiments were conducted by adding the aforesaid catalyst to perform for more than 3 runs.

Blank experiments were carried out without catalysts, achieving 2-10\% in $6 \mathrm{~h}$ of reaction.

The conversion was calculated by the same method as described in detail in Ref. [6], as follows:

Where nglycerol in is the inlet glycerol concentration, and nglycerol out is the outlet glycerol concentration time $t(\mathrm{~h})$.

$$
\% \text { Glycerol conversion }(t)=\frac{[\text { (nglycerol }) \text { in }-(\text { nglycerol }) \text { out }]}{(\text { nglycerol }) \text { out }} \times 100
$$

Selectivity was calculated according to the equation:

$$
\% \text { Selectivity }=\frac{\text { Mol percentage of desired product }}{\sum \text { Mol percentage of all product obtained }} \times 100
$$




\section{Conclusions}

Metal-containing HAPs were investigated in esterification of glycerol in the presence of acetic acid. The reasons of the deactivation behavior of $\mathrm{Co}$ and Ni-containing HAPs in short reaction runs were the lack of stability of these $\mathrm{Co}^{2+}$ and $\mathrm{Ni}^{2+}$ cations into the HAP lattice as a consequence of their leaching from the catalyst. On the other hand, the copper lost was not enough reason for the observed slight activity decay of $\mathrm{Cu}$-containing HAPs. The $\mathrm{Cu}^{2+}$ cations either substituted for $\mathrm{Ca}^{2+}$ into the hexagonal channels or in the vacancies were beneficial to the stability of active sites due to the acid center $\mathrm{Cu}^{2+}-\mathrm{OH}$ pairs, but, also, the presence of $\mathrm{Cu}^{+}$species favored the EG reaction. Regarding the metal contents, glycerol conversion raised as the metal contents increased due to the available active sites for the reaction, with triacetin being preferentially formed upon, prolonging the reaction times. High $\mathrm{Cu}$ contents up to $9.0 \%$ achieved glycerol conversions superior to $30 \%$ after $6 \mathrm{~h}$ reaction at a glycerol to acid acetic ratio of 0.25 and temperature of $80^{\circ} \mathrm{C}$. Moreover, $\mathrm{Cu}$-containing HAPs having a $\mathrm{Cu}$ content of ca. $17 \%$ were stable and reusable during five consecutive cycles of $\mathrm{EG}$ reaction, in contrast to $\mathrm{Cu}$ and $\mathrm{Ni}$ counterparts, that deactivated in the first and third runs.

Author Contributions: G.M., J.V.C.d.C., A.C., G.D., E.C.d.S.F. and J.M.S. performed the experiments; A.C.O., E.R.-C. and E.R.-A. analyzed the data and wrote the manuscript; G.D.S. and C.B.P. designed and performed the experiments and analyzed the data, as well. All authors have read and agreed to the published version of the manuscript.

Funding: We are grateful to the CNPq Grant (406629/2018-8) and Petrobras ('Física do Petróleo em Meios Porosos' project number: F0185) for the financial support of this work. E.R.C. and E.R.A thank to project RTI2018-099668-BC22 of Ministerio de Ciencia, Innovación y Universidades, and project UMA18-FEDERJA-126 and P20_00375 of Junta de Andalucía and FEDER funds.

Acknowledgments: The Central Analítica da Universidade Federal do Ceará and Cetene are gratefully acknowledged for the work on some characterizations of the catalysts. G.M., and we give thanks to Cnpq/Pibic for her scholarship. G.M. and to CNPq/Pibic for the scholarship. J.V.C. acknowledges CAPES for his master scholarship.

Conflicts of Interest: The authors declare no conflict of interest.

\section{References}

1. Mamtani, K.; Shahbaz, K.; Farid, M.M. Glycerolysis of free fatty acids: A review. Renew. Sustain. Energy Rev. 2021, 137, 110501. [CrossRef]

2. $\quad$ Alves, N.F.; Neto, A.B.S.; Bessa, B.D.S.; Oliveira, A.C.; Mendes Filho, J.; Campos, A.F. Binary Oxides with Defined Hierarchy of Pores in the Esterification of Glycerol. Catalysts 2016, 6, 151. [CrossRef]

3. Mou, R.; Wang, X.; Wang, Z.; Zhang, D.; Yin, Z.; Lv, Y.; Wei, Z. Synthesis of fuel bioadditive by esterification of glycerol with acetic acid over hydrophobic polymer-based solid acid. Fuel 2021, 302, 121175. [CrossRef]

4. Carlucci, C.A. Focus on the Transformation Processes for the Valorization of Glycerol Derived from the Production Cycle of Biofuels. Catalysts 2021, 11, 280. [CrossRef]

5. Magar, S.; Mohanraj, G.T.; Jana, S.K.; Rode, C.V. Synthesis and characterization of supported heteropoly acid: Efficient solid acid catalyst for glycerol esterification to produce biofuel additives. Inorg. Nano-Met. Chem. 2020, 50, 1157-1165. [CrossRef]

6. Costa, D.; Carmo, J.V.; Oliveira, A.C.; Araújo, J.C.S.; Campos, A.; Duarte, G.C.S. Synthesis of highly porous alumina-based oxides with tailored catalytic properties in the esterification of glycerol. J. Mater. Res. 2018, 33, 3625-3633. [CrossRef]

7. Malaik, A.; Ptaszyńsk, K.; Kozłowski, M. Conversion of renewable feedstock to bio-carbons dedicated for the production of green fuel additives from glycerol. Fuel 2021, 288, 119609. [CrossRef]

8. Neto, A.B.S.; Oliveira, A.C.; Rodriguez-Castellón, E.; Campos, A.F.; Freire, P.T.C.; Sousa, F.F.F.; Filho, J.M.; Araujo, J.C.S.; Lang, R.A. A comparative study on porous solid acid oxides as catalysts in the esterification of glycerol with acetic acid. Catal. Today 2020, 349, 57-67. [CrossRef]

9. Valter, M.; dos Santos, E.C.; Pettersson, L.G.M.; Hellman, A. Selectivity of the First Two Glycerol Dehydrogenation Steps Determined Using Scaling Relationships. ACS Catal. 2021, 11, 3487-3497. [CrossRef]

10. Canck, E.D.; Dosuna-Rodríguez, I.; Gaigneaux, E.M.; Van Der Voort, P. Periodic Mesoporous Organosilica Functionalized with Sulfonic Acid Groups as Acid Catalyst for Glycerol Acetylation. Materials 2013, 6, 3556-3570. [CrossRef]

11. Zaher, S.; Christ, L.; El Rahim, M.A.; Kanj, A.; Karamé, I. Green acetalization of glycerol and carbonyl catalyzed by $\mathrm{FeCl}_{3} \cdot 6 \mathrm{H}_{2} \mathrm{O}$. Mol. Catal. 2017, 438, 204-213. [CrossRef] 
12. Kale, S.S.; Armbruster, U.; Eckelt, R.; Bentrup, U.; Umbarkar, S.B.; Dongare, M.K.; Martin, A. Understanding the role of Keggin type heteropolyacid catalysts for glycerol acetylation using toluene as an entrainer. Appl. Catal. A Gen. 2016, 527, 9-18. [CrossRef]

13. Betiha, M.A.; Hassan, H.M.A.; El-Sharkawy, E.A.; Al-Sabagh, A.M.; Menoufy, M.F.; Abdelmoniem, H.M. Application for glycerol acetylation using robust sustainable acidic heterogeneous-homogenous catalyst. Appl. Catal. B Environ. 2016, $182,15-25$. [CrossRef]

14. Zhou, L.; Al-Zaini, E.; Adesina, A.A. Catalytic characteristics and parameters optimization of the glycerol acetylation over solid acid catalysts. Fuel 2013, 103, 617-625. [CrossRef]

15. Kong, P.S.; Aroua, M.K.; Daud, W.M.A.W.; Lee, H.V.; Cognet, P.; Perez, Y. Catalytic role of solid acid catalysts in glycerol acetylation for the production of bio-additives: A review. RSC Adv. 2016, 6, 68885. [CrossRef]

16. Osatiashtiani, A.; Puértolas, B.; Oliveira, C.C.S.; Manayil, J.C.; Pérez-Ramírez, J.; Barbero, B.; Isaacs, M.; Michailof, C.; Heracleous, E.; Lee, A.F.; et al. On the influence of Si:Al ratio and hierarchical porosity of FAU zeolites in solid acid catalysed esterification pretreatment of bio-oil. Biomass Conv. Biorefin. 2017, 7, 331-342. [CrossRef]

17. Suprum, W.; Lutecki, M.; Glaser, R.; Paap, H. Catalytic activity of bifunctional transition metal oxide containing phosphated alumina catalysts in the dehydration of glycerol. J. Mol. Catal. A Chem. 2011, 342, 91-100. [CrossRef]

18. Carvalho, D.C.; Pinheiro, L.G.; Oliveira, A.C.; Millet, E.R.C.; de Sousa, F.F.; Saraiva, G.D.; da Silva Filho, E.C.; Fonseca, M.G. Characterization and catalytic performances of copper and cobalt-exchanged hydroxyapatite in glycerol conversion for 1-hydroxyacetone production. Appl. Catal. A Gen. 2014, 471, 39-49. [CrossRef]

19. Silvester, L.; Lamonier, J.-F.; Vannier, R.-N.; Lamonier, C.; Capron, M.; Mamede, A.-S.; Pourpoint, F.; Gervasini, A.; Dumeignil, F. Structural, textural and acid-base properties of carbonate-containing hydroxyapatites. J. Mater. Chem. A 2014, 2, 11073-11090. [CrossRef]

20. Ebadipour, N.; Paul, S.; Katryniok, B.; Dumeignil, F. Calcium Hydroxyapatite: A Highly Stable and Selective Solid Catalyst for Glycerol Polymerization. Catalysts 2021, 11, 1247. [CrossRef]

21. Liu, Z.H.; Yan, B.; Liang, Y.; Xu, B.Q. Comparative study of gas-phase "dehydration" of alkyl lactates and lactic acid for acrylic acid production over hydroxyapatite catalysts. Mol. Catal. 2020, 494, 111370. [CrossRef]

22. Bolis, V.; Busco, C.; Gianmario, M.; Bertinetti, L.; Sakhno, Y.; Ugliengo, P.; Chiatti, F.; Corno, M.; Roveri, N. Coordinationchemistry of $\mathrm{Ca}$ sites at the surface of nanosized hydroxyapatite: Interaction with $\mathrm{H}_{2} \mathrm{O}$ and CO. Philos. Trans. R. Soc. A 2012, 370, 1313-13236. [CrossRef]

23. Coelho, D.C.; Oliveira, A.C.; Filho, J.M.; Oliveira, A.C.; Lucredio, A.F.; Assaf, E.M.; Rodríguez-Castellón, E. Effect of the active metal on the catalytic activity of the titanate nanotubes for dry reforming of methane. Chem. Eng. J. 2016, 290, 438-453. [CrossRef]

24. Khayoon, M.S.; Hameed, B.H. Yttrium-grafted mesostructured SBA-3 catalyst for the transesterification of glycerol with methyl acetate to synthesize fuel oxygenates. Appl. Catal. A Gen. 2013, 460-461, 61-69. [CrossRef]

25. Kotbagi, T.V.M.; Pandhare, S.L.; Dongare, M.; Umbarkar, S. In situ Formed Supported Silicomolybdic Heteropolyanions: Efficient Solid Catalyst for Acetylation of Glycerol. J. Environ. Anal. Chem. 2015, 2, 2380-2391.

26. Liao, Y.; Zhu, Y.; Wang, S.-G.; Li, Y. Producing triacetylglycerol with glycerol by two steps: Esterification and acetylation. Fuel Process. Technol. 2009, 90, 988-993. [CrossRef]

27. Landau, M.V.; Hos, T.; Nehemya, R.V.; Nomikos, G.; Herskowitz, M. Eco-Friendly and Sustainable Process for Converting Hydrous Bioethanol to Butanol. Catalysts 2021, 11, 498. [CrossRef]

28. Guo, J.; Yu, H.; Dong, F.; Zhu, B.; Huang, W.; Zhang, S. High efficiency and stability of Au-Cu/hydroxyapatite catalyst for the oxidation of carbon monoxide. High efficiency and stability of $\mathrm{Au}-\mathrm{Cu} /$ hydroxyapatite catalyst for the oxidation of carbon monoxide. RSC Adv. 2017, 7, 45420. [CrossRef]

29. Chang, Q.; Xu, W.; Li, N.; Xue, C.; Wang, Y.; Li, Y.; Wang, H.; Yang, Y.; Hu, S. Dynamic restructuring of carbon dots/copper oxide supported on mesoporous hydroxyapatite brings exceptional catalytic activity in the reduction of 4-nitrophenol. Appl. Catal. B Environ. 2020, 263, 118299. [CrossRef]

30. Belik, A.A.; Koo, H.-J.; Whangbo, M.-H.; Tsujii, N.; Naumov, P.; Takayama-Muromachi, E. Magnetic Properties of Synthetic Libethenite $\mathrm{Cu}_{2} \mathrm{PO}_{4} \mathrm{OH}$ : A New Spin-Gap System. Inorg. Chem. 2007, 46, 8684-8689. [CrossRef]

31. Kramer, E.; Itzkowitz, E.; Wei, M. Synthesis and characterization of cobalt-substituted hydroxyapatite powders. Ceram. Inter. 2014, 40, 13471-13480. [CrossRef]

32. Dayan, C.; Giraudon, J.M.; Labaki, M.; Lamonier, J.-F. Formaldehyde Total Oxidation on Manganese-Doped Hydroxyapatite: The Effect of Mn Content. Catalysts 2020, 10, 1422.

33. Stanic, V.; Dimitrijevic, S.; Stankovi, J.A.; Mitric, M.; Jokic, B.; Pleca, I.B.; Raicevi, S. Synthesis, characterization and antimicrobial activity of copper and zinc-doped hydroxyapatite nanopowders. Appl. Surf. Sci. 2010, 256, 6083-6089. [CrossRef]

34. Carvalho, D.C.; Oliveira, A.C.; Ferreira, O.P.; Filho, J.M.; Tehuacanero-Cuapa, S.; Oliveira, A.C. Titanate nanotubes as acid catalysts for acetalization of glycerol with acetone: Influence of the synthesis time and the role of structure on the catalytic performance. Chem. Eng. J. 2017, 313, 1454-1467. [CrossRef]

35. Neira, I.S.; Kolen'ko, Y.V.; Lebedev, O.I.; Tendeloo, G.V.; Gupta, H.S.; Guitián, F.; Yoshimura, M. An Effective Morphology Control of Hydroxyapatite Crystals via Hydrothermal Synthesis. Cryst. Growth Des. 2009, 9, 466-474. [CrossRef]

36. Putrakumar, B.; Seelam, P.K.; Srinivasarao, G.; Rajan, K.; Rajesh, R.; Rao, K.R.; Liang, T. High Performance and Sustainable Copper-Modified Hydroxyapatite Catalysts for Catalytic Transfer Hydrogenation of Furfural. Catalysts 2020, 10, 1045. [CrossRef] 
37. Gabbasov, B.; Gafurov, M.; Starshov, A.; Mamin, G.; Orlinskii, S. Conventional, pulsed and high-field electron paramagnetic resonance for studying metal impurities in calcium phosphates of biogenic and synthetic origins. J. Magn. Magn. Mater. 2019, 470, 109-117. [CrossRef]

38. Sadło, J.; Lukasz, P.; Michalik, J.; Kolodziejski, W. EPR studies of radicals generated by c-radiation in nanocrystalline hydroxyapatites prepared by dry milling. J. Mol. Struct. 2012, 1022, 61-67. [CrossRef]

39. Carmo, J.C.; Lima, C.L.; Mota, G.; Santos, A.M.S.; Costa, L.N.; Ghosh, A.; Viana, B.C.; Silva, M.; Soares, J.M.; Tehuacanero-Cuapa, S.; et al. Effects of the Incorporation of Distinct Cations in Titanate Nanotubes on the Catalytic Activity in $\mathrm{NO}_{x}$ Conversion. Materials 2021, 14, 2181. [CrossRef]

40. Oliveira, A.P.S.; Gomes, I.S.; Neto, A.S.B.; Oliveira, A.C.; Filho, J.M.; Saraiva, G.D.; Soares, J.M.; Tehuacanero-Cuapa, S. Catalytic performance of MnFeSi composite in selective oxidation of styrene, ethylbenzene and benzyl alcohol. Mol. Catal. 2017, 436, 29-42. [CrossRef]

41. Lamkhao, S.; Phaya, M.; Jansakun, C.; Chandet, N.; Thongkorn, K.; Rujijanagul, G.; Bangrak, P.; Randorn, C. Synthesis of Hydroxyapatite with Antibacterial Properties Using a Microwave-Assisted Combustion Method. Sci. Rep. 2019, 9, 4015. [CrossRef]

42. Nosenko, V.; Strutynska, N.; Vorona, I.; Zatovsky, I.; Volodymyr Dzhagan, V.; Lemishko, S.; Epple, M.; Prymak, O.; Baran, N.; Ishchenko, S.; et al. Structure of biocompatible coatings produced from hydroxyapatite nanoparticles by detonation spraying. Nanoscale Res. Lett. 2015, 10, 464. [CrossRef]

43. Li, Y.; An, D.; Zhang, Q.; Wang, Y. Copper-Catalyzed Selective Oxidation of Methane by Oxygen: Studies on Catalytic Behavior and Functioning Mechanism of $\mathrm{CuO}_{\mathrm{x}}$ /SBA-15. J. Phys. Chem. C 2008, 112, 13700-13708. [CrossRef]

44. Liu, L.; Wu, X.; Ma, Y.; Zhang, X.; Ran, R.; Si, Z.; Weng, D. Potassium deactivation of Cu-SSZ-13 catalyst for $\mathrm{NH}_{3}-\mathrm{SCR}$ : Evolution of salts, zeolite and copper species. Chem. Eng. J. 2020, 383, 123080. [CrossRef]

45. Weckhuysen, B.M.; Verberckmoes, A.A.; Uytterhoeven, M.G.; Mabbs, F.E.; Collison, D.; de Boer, E.; Schoonheydt, R.A. Electron Spin Resonance of High-Spin Cobalt in Microporous Crystalline Cobalt-Containing Aluminophosphates. J. Phys. Chem. B 2000, 104, 37-42. [CrossRef]

46. Natte, K.; Jagadeesh, R.V.; Sharif, M.; Neumann, H.; Beller, M. Synthesis of nitriles from amines using nanoscale $\mathrm{Co}_{3} \mathrm{O}_{4}$-based catalysts via sustainable aerobic oxidation. Org. Biomol. Chem. 2016, 14, 3356-3359. [CrossRef]

47. Hashem, M.; Saion, E.; Al-Hada, N.M.; Kamari, H.M.; Shaari, A.H.; Tali, Z.A.; Paiman, S.B.; Kamarudeen, M.A. Fabrication and characterization of semiconductor nickel oxide (NiO) nanoparticles manufactured using a facile thermal treatment. Results Phys. 2016, 6, 1024-1030. [CrossRef]

48. Chandra, S.; Gupta, L.K. EPR and electronic spectral studies on Co(II), Ni(II) and Cu(II) complexes with a new tetradentate [N4] macrocyclic ligand and their biological activity. Spectrochim. Acta Part A Mol. Biomol. Spectrosc. 2004, 60, 1563-1571. [CrossRef]

49. Maachou, H.; Genet, M.J.; Aliouche, D.; Dupont-Gillain, C.C.; Rouxhet, P.G. XPS analysis of chitosan-hydroxyapatite biomaterials: From elements to compounds. Surf. Inter. Anal. 2013, 45, 1088-1097. [CrossRef]

50. Lu, H.B.; Campbell, C.T.; Graham, D.J.; Ratner, B.D. Surface Characterization of Hydroxyapatite and Related Calcium Phosphates by XPS and TOF-SIMS. Anal. Chem. 2000, 72, 2886-2894. [CrossRef]

51. Li, J.; Li, Y.; Zhang, L.; Zuo, Y. Composition of calcium deficient Na-containing carbonate hydroxyapatite modified with Cu (II) and Zn (II) ions. Appl. Surf. Sci. 2008, 254, 2844-2850. [CrossRef]

52. Elkabouss, K.; Kacimi, M.; Mahfou, M.; Ziyad, M.; Souad, A.; Bozon-Verduraz, F. Cobalt-exchanged hydroxyapatite catalysts: Magnetic studies, spectroscopic investigations, performance in 2-butanol and ethane oxidative dehydrogenations. J. Catal. 2004, 226, 16-24. [CrossRef]

53. Pang, Y.; Konga, L.; Chen, D.; Yuvarajaa, G.; Mehmood, S. Facilely synthesized cobalt doped hydroxyapatite as hydroxyl promoted peroxymonosulfate activator for degradation of Rhodamine B. J. Hazard. Mater. 2020, 384, 121447. [CrossRef] [PubMed]

54. Boukh, Z.; Kacimi, M.; Pereira, M.F.R.; Faria, J.L.; Figueiredo, J.L.; Ziyada, M. Methane dry reforming on Ni loaded hydroxyapatite and fluoroapatite. Appl. Catal. A Gen. 2007, 317, 299-309. [CrossRef]

55. Akri, M.; Zhao, S.; Li, X.; Zang, K.; Lee, A.F.; Isaacs, M.A.; Xi, W.; Gangarajula, Y.; Luo, J.; Ren, Y.; et al. Atomically dispersed nickel as coke-resistant active sites for methane dry reforming. Nat. Commun. 2019, 10, 5181. [CrossRef] 